\title{
Design Analysis and Observed Performance of a Tieback Anchored Pile Wall in Sand
}

\author{
Jian-Yong Han, ${ }^{1}$ Wen Zhao, ${ }^{1}$ Yang Chen, ${ }^{1}$ Peng-Jiao Jia, ${ }^{1}$ and Yong-Ping Guan ${ }^{2}$ \\ ${ }^{1}$ School of Resource \& Civil Engineering, Northeastern University, Shenyang 110819, China \\ ${ }^{2}$ China Railway Design Corporation, Tianjin 300142, China
}

Correspondence should be addressed to Wen Zhao; wenneu@163.com

Received 17 July 2017; Accepted 29 November 2017; Published 27 December 2017

Academic Editor: Yakov Strelniker

Copyright (C) 2017 Jian-Yong Han et al. This is an open access article distributed under the Creative Commons Attribution License, which permits unrestricted use, distribution, and reproduction in any medium, provided the original work is properly cited.

This paper aims to study the design process and service performance of a deep excavation supported by tieback anchored pile walls. The design procedure and design approaches for deep excavation in China are described. Based on the excavation case history for Shenyang, China, design results obtained using the elastic method and the finite element method (FEM) are compared and analyzed. Special emphasis is given to the analysis of horizontal wall deformations, internal forces in the wall, earth pressures on the wall, ground surface settlements, and stabilities of the excavation. The similarities and differences between the Chinese code (JGJ 120-2012) and the European code (EN 1997-1) for the design of geotechnical structures are presented based on a design example. Through the comparison, it is indicated that the Chinese code focuses on the design result, while the European code focuses on the design process. The crucial construction methods for reducing construction risk based on the excavation case history are described. The mechanical behaviors of the excavation retained by an anchored pile wall were investigated by analyzing observed field cases. The results provide good, practical guidelines for the design and construction of a tieback anchored pile wall retained excavation in sandy soil.

\section{Introduction}

As the number of deeper and wider excavations in urban districts increases, the use of retaining structures to overcome problems related to settlement and bearing capacity is becoming more common. The use of tieback anchored retaining walls has been a widely adopted practice in geotechnical engineering, especially for deep excavations [1]. The service performance of tiebacks and walls for the retaining of deep excavations in urban environments is important because of the need to ensure the safety of adjacent structures and buildings. This technique has been developed over the last seven decades not only for design but also for construction and testing [2]. While design and construction recommendations and guidelines are largely presented in the literature, they are somewhat considered to provide only general indicative guidance. Design methods and design results need to be analyzed more systematically. Knowledge and experience related to observed performances under local ground conditions are also required and are thought to be the most valuable tools for ensuring a safe, effective, and economical design.
Our understanding of the design of tieback anchored walls has improved since the emergence of geotechnical engineering design standards in different countries. An increasing number of researchers and engineers have contributed to the development of design methods over the last three decades to provide helpful, practical guidance (e.g., Briaud and Lim [3] and Lambe and Hansen [4]). Weatherby [5] studied the behavior of tieback H-beam walls to improve the design of tieback walls and provide optimization methods for design. Recommendations, in terms of apparent earth pressures, wall and ground movement control, the use of limiting equilibrium methods for design, and so on, were presented. Khoshnevisan et al. [6] proposed a robust geotechnical design (RGD) approach involving optimization to obtain a design that is safe, economic, and robust. For complex geotechnical conditions and structures, the modified RGD approach was shown to be more competitive than the traditional design methods. The studies cited above show that the design of tieback anchored walls remains a problem.

Since the publication of Peck [7], lots of researchers have devoted themselves to the analysis of field measurements 
to reveal the performances of excavations and retaining structures (e.g., O’Rourke, 1981 [8]; Finno et al., 1989 [9]; Ou et al., 1998 [10]; Finno et al., 2007 [11]; and Tan and Wei, 2011 [12]). With the increasing employment of tieback anchored retaining walls, the analysis of the mechanical behavior for an excavation supported by tieback walls is also prevalent in the available literature. Seo et al. [13] carried out 12 types of model tests for the case of a tieback anchored wall in sand. Based on the model tests, prediction methods were proposed to evaluate the behaviors of an anchored wall in sand. Finno and Roboski [14-16] conducted a series of analyses of a deep tieback excavation in Chicago clay that involved extensive field performance data and three-dimensional numerical models. The maximum horizontal ground movements for retaining structures were determined as a function of the safety factor against basal heave and excavation depth. The existing literature mostly presents the service behaviors of retaining walls, while the performances of ground anchors need to be studied further.

This study focuses on the design, construction, testing, and monitoring of a deep excavation retained by a tieback anchored pile wall in Shenyang, China. A detailed analysis of the design of tieback walls, including the design procedure, design approaches, and design theory, is conducted. The design results are compared with calculations made using the finite element method (FEM) and observations based on an excavation case. The similarities and differences between the Chinese and European codes for the design of geotechnical structures are analyzed using a design example. The observed performance of a tieback anchored pile wall in sand, which serves as an excellent guide for structural design, is presented by analyzing the test results and in situ measurements. This study provides information that is useful for the design and construction of deep excavations supported by anchored pile walls.

\section{Previous Work}

The design method of tieback anchored wall or cantilever pile wall for deep excavation has been studied for about 60 years. In 1943, Terzaghi [17] (1943) proposed two classical geotechnical limit problems, that is, stability problems and elasticity problems, which were developed and were evolved to be two limit states, that is, ultimate limit states and serviceability limit states. At that time, global or total safety factors were widely used for geotechnical design in Europe, the United States, Canada, and other countries. The customary total safety factors are listed in Table 1. Different safety factor values were applied to different conditions, such as the bearing capacity, service condition, and temporary works.

After the 1950s, with the development of the theory of soil mechanics, it was believed that total safety factors cannot satisfy the requirements of geotechnical design based on the limit states. Taylor [18] and Brinch Hansen $[19,20]$ proposed the concepts of separate safety factors, that is, the partial factors. Consequently, many researchers studied the recommended values of partial factors and the application of geotechnical design. Simpson [21] described the purposes and basic requirement of the partial factors.
TABLE 1: Recommendations of total safety factors.

\begin{tabular}{lc}
\hline Item & Safety factor \\
\hline Earthworks & $1.3-1.5$ \\
Retaining structures, excavations, offshore foundations & $1.5-2$ \\
Foundations on land & $2-3$ \\
Pile load tests & $1.5-2$ \\
Dynamic formulas & 3 \\
\hline
\end{tabular}

Based on four design examples, the insufficient of European code EN 1997-1 was analyzed. He believed that the design resistance offered by structural elements or zone of ground was uncertain, which needed a resistance model to determine the partial factors. He also indicated that some uncertainties, such as ground levels and water levels, were better to adjust the parameters directly, rather than adjust the safety factors. Orr [22] presented the selection of characteristic strength values and partial factors in geotechnical designs according to Eurocode 7. A rational method was proposed to derive the characteristic values from the observations. In addition, examples were conducted, which showed the importance of using partial factor in geotechnical design. Becker [23] described and discussed the reliability-based design approaches, in terms of their differences, advantages, and limitations. The European design approach and the North American design approach were compared and analyzed.

For the comparison between European code and Chinese code for geotechnical design, Li et al. [24] mainly introduced the European geotechnical design code and the partial coefficient method based on the theory of probability limit. The differences between the European code and the Chinese code were analyzed. However, the discussions between the European code and the Chinese code need further investigations.

The performances of tieback anchors used to reinforce the ground such as pullout capacity, load changes during excavation, prestress loss, and antifatigue performance have been studied using different techniques, including physical models, finite element models, and field investigations. Kim [25] performed seven ground anchor pullout tests in weathered soil, including four compression type anchors and three tension type anchors. According to a seven-day relaxation test, the prestress losses of anchors were observed. Furthermore, a relationship between predicted prestress loss and creep movement was proposed. However, the predicted prestress loss mainly considered the effect of creep movement, in which the initial prestress loss was not considered. Konstantakos [26] selected 39 deep excavations to investigate the performance and prediction of tieback wall supporting excavations. According to the comparison of various observations from excavation case histories, one of the crucial influence factors of pile wall deformation was tieback creep and prestress loss. Tamano et al. [27], Uğur Terzi et al. [28], and Hsu [29] conducted a number of field tests in different geotechnical conditions. The anchorage capacities and service performances of various ground anchors were investigated. 


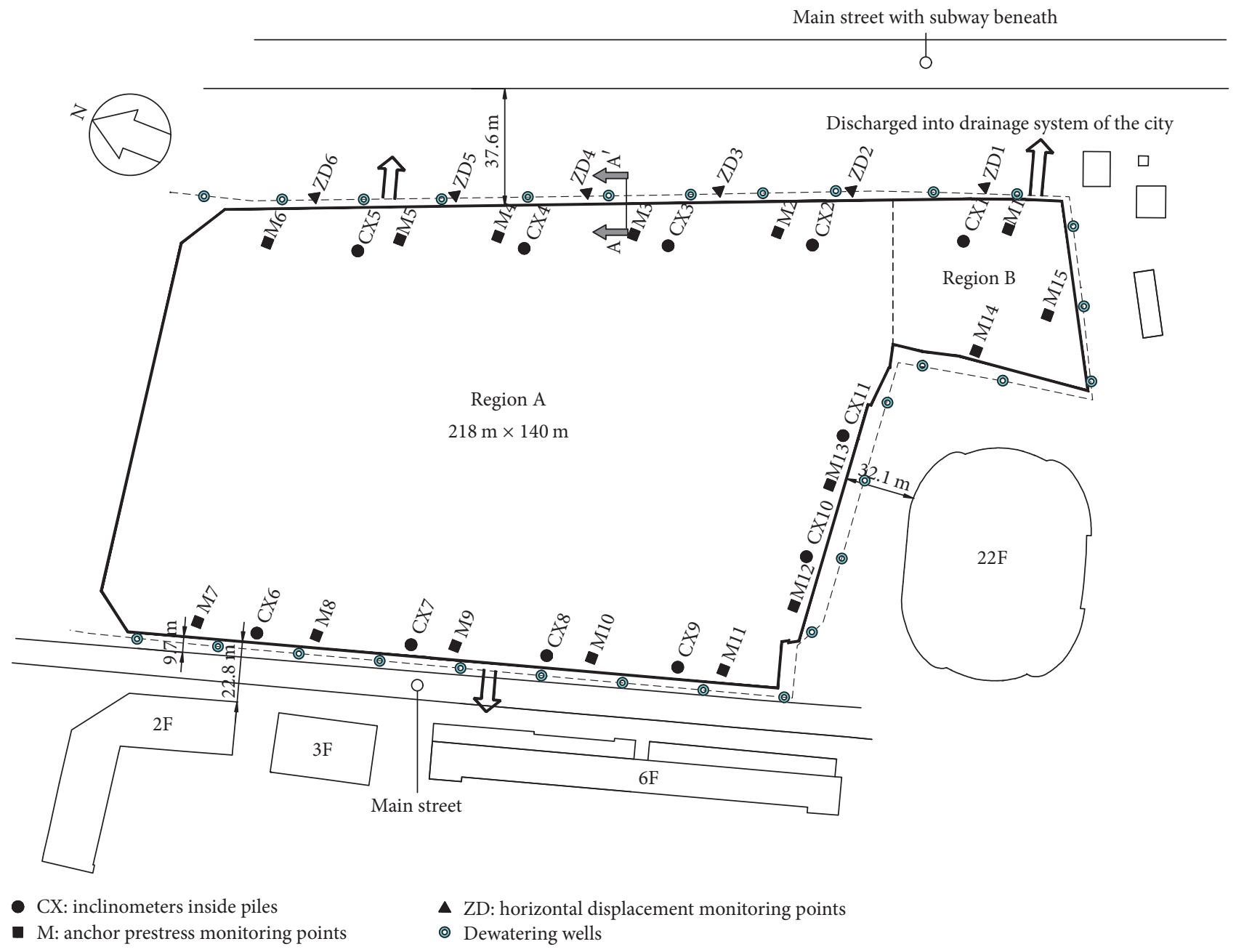

FIGURE 1: Site layout and monitoring plan.

\section{Project Background}

3.1. Project Overview. The deep excavation studied in this paper was located in one of the central districts of Shenyang, China, with busy roads and buildings existing around it. The excavation was divided into two regions, that is, Region $\mathrm{A}$ and Region B (see Figure 1), and had a total area of $33,548 \mathrm{~m}^{2}$. The average excavation depths of Region A and Region B were $23.1 \mathrm{~m}$ and $14.9 \mathrm{~m}$, respectively, and the areas were $218 \times$ $140 \mathrm{~m}^{2}$ and $55 \times 40 \mathrm{~m}^{2}$, respectively. Many buildings, which are all masonry structures, are located near the west side of the deep excavation, with a minimum distance of $22.8 \mathrm{~m}$ between the excavation and buildings. A building with 22 floors above ground and 2 floors underground is located $32.1 \mathrm{~m}$ south of Region A. Pipelines and a metro tunnel exist beneath the main street east of the deep excavation. Thus, strict deformation values of the excavation and surroundings are required.

The retaining pile walls used for the deep excavation were all supported by prestressed tieback anchors. The soils between the piles were reinforced using mesh reinforcement and shotcrete. The pile walls used to support Region $\mathrm{A}$ and Region $\mathrm{B}$, with a diameter of $0.6 \mathrm{~m}$ and a pile spacing of
$1.1 \mathrm{~m}$, were reinforced by seven and three levels of prestressed tieback anchors, respectively, with a $3 \mathrm{~m}$ vertical spacing on average. $L 1-L 7$ represent the seven rows of tieback anchors. The heads of the tieback anchors were fixed onto two Usteel wales. The tieback anchors were made of three or four steel strands with a tensile strength of $1860 \mathrm{MPa}$ and installed with $15^{\circ}$ horizontal angle. The horizontal spacings used for the tieback anchors were $2.2 \mathrm{~m}$ for $L 2$ and $L 3$ and $1.1 \mathrm{~m}$ for the remaining five rows. Figure 2 shows the design parameters and profile of the retaining structures. The pile wall installed between Region A and Region B was made using the same material mentioned, with one level of prestressed tieback anchors.

3.2. Hydrological and Geological Conditions. A geotechnical investigation was carried out through the boreholes at the excavation construction site, which showed that the in situ soils included a Quaternary Holocene artificial filling soil layer, Quaternary Holocene Hun River floodplains and paleocurrent shock layer, and Quaternary Hun River rushed diluvium. The in situ soils, including medium-coarse sand and gravelly sand with a dense or medium dense state, show the mechanical behavior of coarse-grained sand 

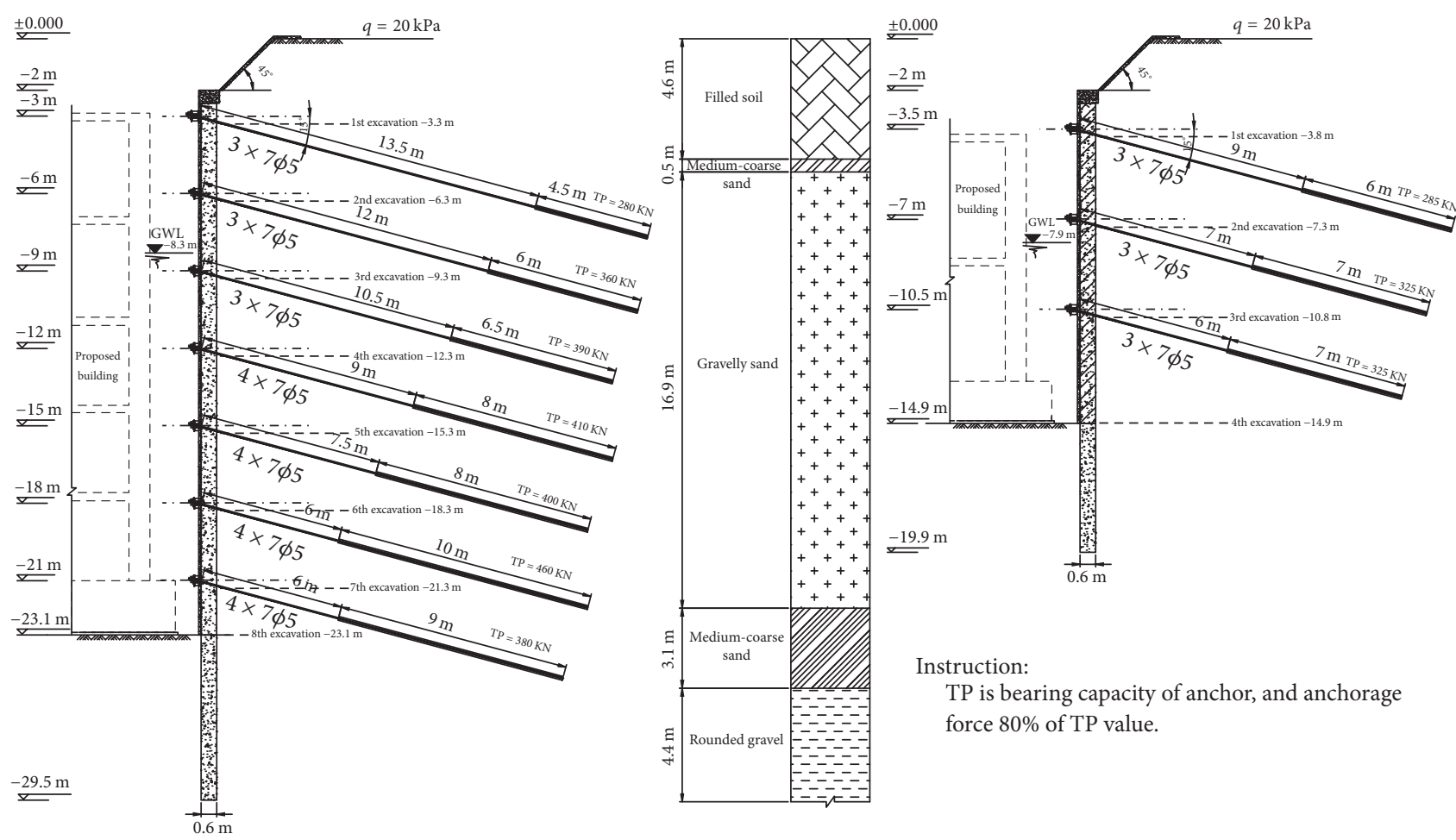

FIGURE 2: Cross-section profile of retaining structure.

TABLE 2: Mechanical parameters of soils.

\begin{tabular}{|c|c|c|c|c|c|c|c|}
\hline Number & Soil & Depth/m & Unit weight $/ \mathrm{kN} \cdot \mathrm{m}^{-3}$ & $c / \mathrm{kPa}$ & $E_{s} / \mathrm{MPa}$ & $\varphi /\left(^{\circ}\right)$ & fak $(\mathrm{kPa})$ \\
\hline (1) & Filled soil & 4.6 & 16.66 & - & 15 & 10 & - \\
\hline (2) & Medium-coarse sand & 0.5 & 19.11 & 1 & 18 & 30 & 200 \\
\hline (3) & Gravelly sand & 16.9 & 19.60 & 1 & 30 & 36.4 & 500 \\
\hline (4) & Medium-coarse sand & 3.1 & 19.11 & 1 & 27 & 33.4 & 480 \\
\hline (5) & Rounded gravel & 20.9 & 20.58 & 1 & 40 & 37.8 & 650 \\
\hline
\end{tabular}

[30]. The mechanical parameters of the soils are listed in Table 2.

The groundwater at the site consists of pore phreatic water. The stable groundwater level is approximately $8 \mathrm{~m}$, and the permeability coefficient of the soils ranges from $40 \mathrm{~m} / \mathrm{d}$ to $80 \mathrm{~m} / \mathrm{d}$. The groundwater level inside the excavation was required to be below the bottom of the excavation, which was achieved through dewatering, for normal construction.

\section{Design of Deep Excavation}

\subsection{Design Approach of Deep Excavation in China}

4.1.1. Design Procedure of Deep Excavation. Currently, various retaining technologies are employed in the construction of deep excavations in China, such as cast-in place piles, precast piles, diaphragm walls, and sheet pile walls. It is quite complex to optimize a retaining plan for deep excavation. Hence, design standards are applied with no alternative for construction works to ensure the security and low cost of retaining structures. In China, the recommendations, design approaches, and requirements for the design of deep excavations are presented in one national standard, that is, the Technical Specification for Retaining and Protection of Building Foundation Excavations (JGJ 120-2012) [31], which superseded the former version JGJ 120-99 in 2012. Figure 3 shows the design procedure for a deep excavation adopted by engineers in current design practice. For most deep excavation designs, the primary design parameters are determined based on comparable experiences and recommended values. Then, the design parameters are adjusted repeatedly, considering security and economy, to find an optimal retaining structure.

According to JGJ 120-2012, a design should demonstrate that the retaining structures, ground, and surrounding buildings do not exceed the limit states, ultimate limit states (ULS), and serviceability limit states (SLS). When considering the ultimate limit states, two conditions should be met. The first condition requires that internal failure or excessive deformation of the retaining structure does not occur; that is, the following inequality should be satisfied:

$$
\gamma_{0} S_{d} \leq R_{d}
$$




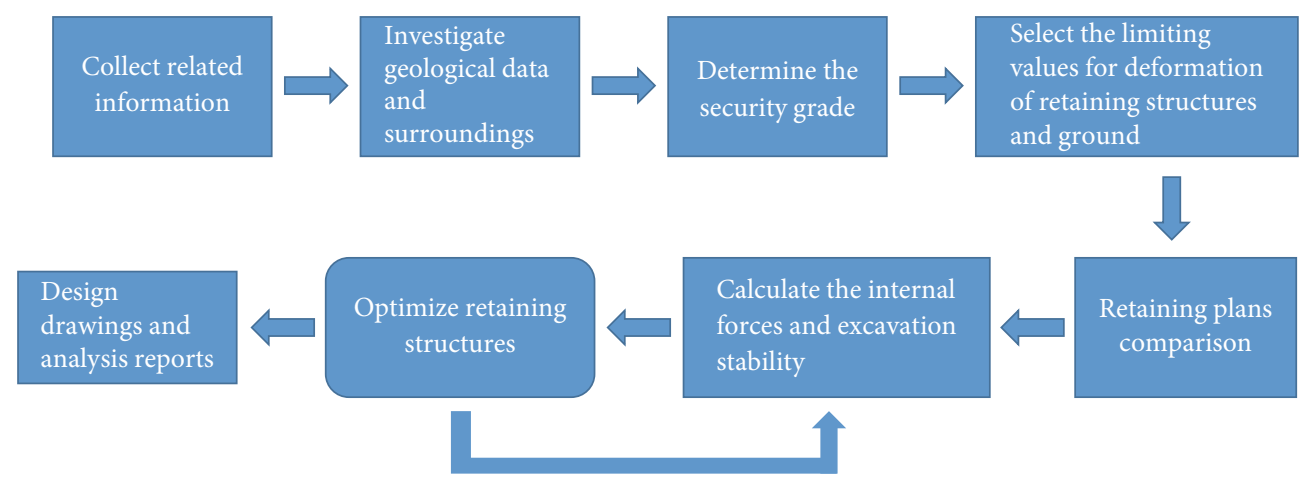

FIGURE 3: Design procedure for deep excavation in China.

TABLE 3: Primary characteristics of classical method and elastic method.

\begin{tabular}{lcccc}
\hline $\begin{array}{l}\text { Calculation } \\
\text { method }\end{array}$ & $\begin{array}{c}\text { Assumption of } \\
\text { strut/anchor }\end{array}$ & Passive earth pressure & Pile stiffness & Calculation theory \\
\hline Classical method & Hinged support & - & Ignored & $\begin{array}{c}\text { Static equilibrium method, equivalent } \\
\text { beam method, etc. }\end{array}$ \\
Elasticity method & Spring & $\begin{array}{c}\text { Winkler elastic } \\
\text { foundation }\end{array}$ & Considered & Beam on Winkler elastic foundation \\
\hline
\end{tabular}

where $\gamma_{0}$ is a factor that depends on the importance of the retaining structure; $S_{d}$ is the design value of the effect of actions; and $R_{d}$ is the design value of the resistance to an action; and for a temporary retaining structure,

$$
S_{d}=\gamma_{F} S_{k}
$$

where $\gamma_{F}$ is the comprehensive partial factor for actions and $S_{k}$ is the characteristic value of the effect of actions.

The second condition requires that loss of stability of the structure or the ground, due to, for example, ground sliding, excavation basal heave, and retaining structure overturning, does not occur; that is, the following inequality should be satisfied:

$$
\frac{R_{k}}{S_{k}} \geq K,
$$

where $R_{k}$ is the characteristic value of the resistance to an action and $K$ is the safety coefficient of stability.

When considering the serviceability limit states, the deformation of structures and surrounding buildings and the ground surface settlement can be verified as follows:

$$
S_{d} \leq C,
$$

where $C$ is the limiting design value of the relevant serviceability criterion.

For this case study, the retaining structures were designed by following the design procedures mentioned in Figure 3. The method of artificial dewatering was effective in this region because of the high permeability of sandy soils; thus, a waterproof curtain was not necessary. Because the area of the excavation was great, a strut-pile wall was not suitable for this project. Thus, the tieback anchored pile wall, which offers good deformational restriction for the structure itself and its surroundings, was selected to be the retaining structure for the excavation. Moreover, the tieback anchored pile wall is commonly used to retain excavations in Shenyang, and designers have many experiences using it in practice.

After the retaining structures were determined, the design parameters were selected via calculations related to the mechanical characteristics and stability of excavation. In China, two geotechnical design software programs, that is, Leading Software-Deep Excavation and Tongji Qim Star Software-FRWS, are commonly used for the calculation and design of deep excavations [32]. In this study, Deep Excavation was chosen for the latter analysis. This program consists of various design modules for the calculation of retaining structures such as soldier pile walls, diaphragm walls, cement soil walls, soil nailing walls, and slopes. The design module for a soldier pile wall includes the calculation of earth pressure and the embedment depth of the wall. The calculations are performed using the following two methods: classical method and elastic method. The calculation assumptions of the two methods are shown in Table 3.

For the classical method, the active and passive pressures are determined according to Rankine theory. The classical method includes the static equilibrium method and equivalent beam method, which are adequate for the design of simple retaining structures, such as cantilever walls and pile walls anchored by a tieback. Compared with the classical method, the elastic method performs the calculation based on the theory of a beam on a Winkler elastic foundation, in which the deformation of the retaining structure is considered. A more realistic earth pressure is obtained using the elastic method, but more accurate parameters are required to ensure a reliable result. Particularly, the stiffness parameters, such as the stiffness coefficient of tiebacks/struts and Young's modulus, greatly influence the calculation results. Thus, if the in situ geotechnical data are accurate, a more reasonable 
TABLE 4: The design parameters of the soil bodies.

\begin{tabular}{lccc}
\hline Number & Soil & $q_{\text {sik }} / \mathrm{kPa}$ & \\
\hline$(1)$ & Filled soil & 20 & 10.0 \\
$(2)$ & Medium-coarse sand & 90 & 15.1 \\
$(3)$ & Gravelly sand & 190 & 23.0 \\
$(4)$ & Medium-coarse sand & 130 & 19.1 \\
$(5)$ & Rounded gravel & 140 & 24.9 \\
\hline
\end{tabular}

result will be obtained using the elastic method. If not, the classical method is the better choice for the primary design $[33,34]$. In this study, the elastic method was selected to verify the stability and resistance of the deep excavation retained by the tieback anchored pile wall in this case history. For this purpose, extensive numerical investigations using the FEM were conducted. The numerical results and observed values were compared with the results calculated using the elastic method to determine the veracity of the design result.

4.1.2. Selection of Parameters. The calculation models of section $\mathrm{AA}^{\prime}$ (see Figure 1) were established using Deep Excavation and the Plaxis finite element program. The first model was established based on the theory of a beam on a Winkler elastic foundation. According to the rules of JGJ 120-2012, the security grade of the deep excavation in this case history was set as Grade 1. Due to this, the values of $\gamma_{0}$ and $\gamma_{F}$ were set to be 1.1 and 1.25 , respectively. A uniform distributed surcharge, $q=20 \mathrm{kPa}$, was employed on the ground surface behind the wall. In this analysis, the ground water was not considered during the excavation construction because the ground water level inside and outside of the excavation was kept below the bottom of the excavation. In addition, according to the stress history of the soils in Shenyang, which will be discussed in Section 4.2, the effect of dewatering on both ground and structure deformations was slight.

The mechanical parameters shown in Table 1 were chosen for each soil layer in the analysis. The ultimate shear stress of the grout-anchor interface for various soils, $q_{\text {sik }}$, was based on the recommendation of JGJ 120-2012, which is listed in Table 4 . The characteristic value of the pullout resistance of tieback anchors, $R_{a, k}$, is defined as follows:

$$
R_{a, k}=\pi d \sum q_{\text {sik }} l_{i},
$$

where $d$ is the diameter of the anchor grout and $l_{i}$ is the fixed length of the anchor in different soil layers. The prestress of each row of anchors was set to be equal to the observed prestress values to allow for comparison with the results of the FEM analysis and the in situ observations. Hence, $L 1=120 \mathrm{kN}, L 2=200 \mathrm{kN}, L 3=180 \mathrm{kN}, L 4=$ $203 \mathrm{kN}, L 5=225 \mathrm{kN}, L 6=224 \mathrm{kN}$, and $L 7=102 \mathrm{kN}$ were selected for both the elastic method and the finite element method.

For the elastic method, the stiffness parameters of the soils and structures are crucial parameters for the prediction of the wall deformation. The horizontal stiffness coefficients of the soils in front of the wall were obtained by using the following formula:

$$
k_{s}=m(z-h),
$$

where $k_{s}$ is the horizontal stiffness coefficients of the soils in front of the wall; $m$ is the proportional coefficient of $k_{s} ; z$ is the depth of the calculated point; and $h$ is the excavation depth in the current construction sequence.

$$
m=\frac{0.2 \varphi^{2}-\varphi+c}{v_{b}},
$$

where $c$ and $\varphi$ are the cohesive force and internal friction angle, respectively, and $v_{b}$ is the horizontal deformation of the wall at the bottom of the excavation. If $v_{b}$ is less than $10 \mathrm{~mm}$, then $v_{b}$ is suggested to be $10 \mathrm{~mm}$ as a recommended value. Thus, the value of $m$ for each soil layer is listed in Table 4.

For the second model, two-dimensional plane stain triangular mesh elements with fifteen displacement nodes were used in the numerical analysis by using Plaxis, an FEM program. Considering the symmetry in deformation, only half of the excavation geometry was modeled (see Figure 4), with a size of $45 \mathrm{~m} \times 120 \mathrm{~m}$. A uniform, distributed surcharge, $q=20 \mathrm{kPa}$, was applied from $2 \mathrm{~m}$ to $10 \mathrm{~m}$ behind the anchored pile wall. All movements were restrained for the bottom boundary, and horizontal movements was restrained for the vertical boundaries.

The soil body was divided into five sublayers according to the geotechnical investigation. The mechanical parameters of each soil sublayer are given in Table 1, and each soil sublayer was assigned with constant Young's modulus values. Two common constitutive models, the linear elastic perfectly plastic Mohr-Coulomb (MC) model and the HardeningSoil (HS) model, were employed in this analysis. The MC model simplifies the stress-strain relation to a linear elastic and perfectly plastic response, with the slope of the elastic part defined as Young's modulus $(E)$. Meanwhile, the HS model implements three Young's moduli as the stiffness parameters for the soils, which include the secant Young's modulus $E_{50}^{\text {ref }}$, the oedometer Young's modulus $E_{\text {oed }}^{\text {ref }}$, and the unloading-reloading Young's modulus $E_{\mathrm{ur}}^{\text {ref }}$. Young's modulus is sensitive and important for estimating the deformation of an excavation but is difficult to estimate reasonably. Due to this, a series of back analyses was performed [35], and the $E_{50}^{\text {ref }}$ value for the HS model was estimated by minimizing the deviation between the observed data and calculation results. As a result, $E_{50}^{\text {ref }}$ was set equal to $4 E_{s}$ for each soil sublayer. $E_{\text {oed }}^{\text {ref }}$ 


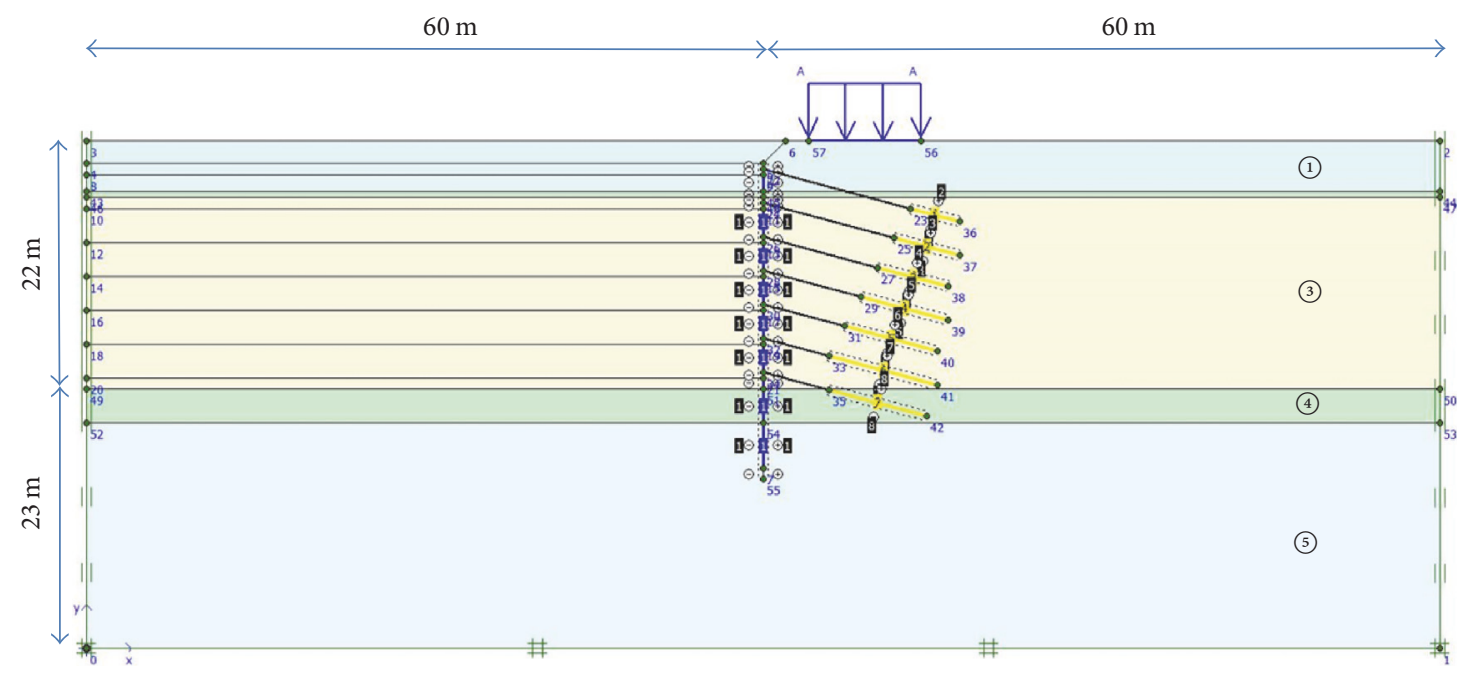

FIGURE 4: Model geometry of the deep excavation.

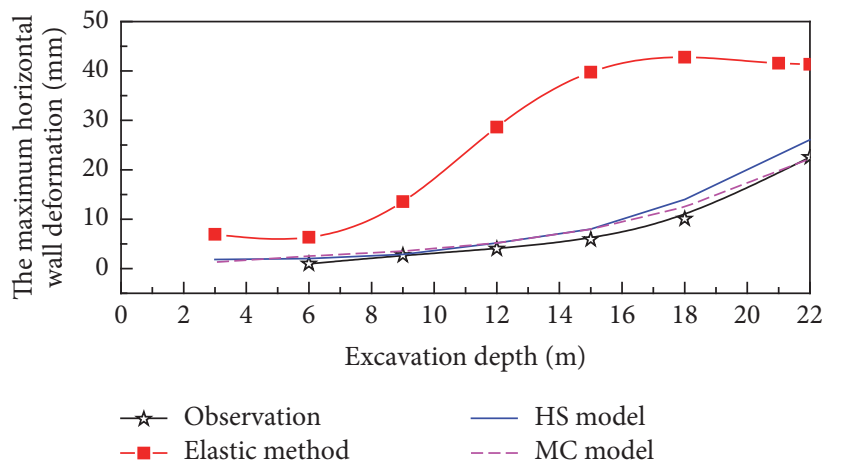

(a)

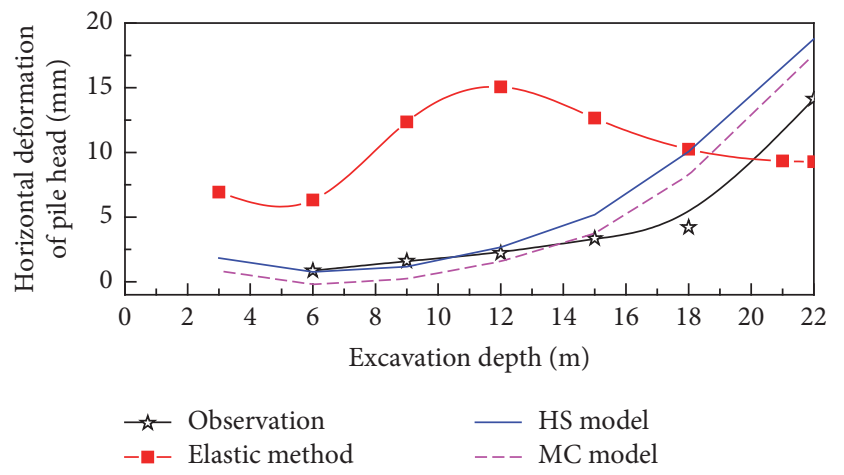

(b)

FIGURE 5: Variation of the maximum wall deformation and the pile head deformation with the excavation depth. (a) The maximum horizontal wall deformation. (b) The horizontal deformation of the pile head.

and $E_{\mathrm{ur}}^{\mathrm{ref}}$ were set to be equal to $E_{50}^{\mathrm{ref}}$ and $3 E_{50}^{\mathrm{ref}}$ for sandy soils, respectively (e.g., Schanz et al., 1999 [36]; Brinkgreve et al., 2010 [37]; and Khoiri et al., 2014 [38]). For the MC model, the $E / E_{50}$ ratio was selected to be equal to 3 for each soil sublayer via back analysis. Interface elements between the soil and the structure were applied to model the soil-structure interaction. The strength parameter $R_{\text {inter }}=0.67$, which means that $\delta=$ $0.67 \varphi$, was used to represent the friction angle between the soil and the structure. The linear elastic model was employed for the pile wall and tieback anchors. To create an equivalent lateral stiffness, the pile wall was replaced by a diaphragm wall with a thickness of $0.4 \mathrm{~m}$ and a length of $27 \mathrm{~m}$. The mechanical parameters of the wall and tiebacks are listed in Table 5.

4.1.3. Analysis Results. To verify the accuracy of the FEM models in simulating the excavation and to examine the design results of the elastic method, the variation curves of the maximum horizontal wall deformation, $\delta_{m}$, and the deformation of the pile head, $\delta_{h}$, are illustrated in Figures 5(a) and 5(b), respectively. Figure 5 indicates that the FEM analysis results for the pile wall deformations were close
TABLE 5: Mechanical parameters of retaining structures.

\begin{tabular}{lccc}
\hline Retaining structure & $\gamma / \mathrm{kN} \cdot \mathrm{m}^{-3}$ & $E / \mathrm{GPa}$ & $\mu$ \\
\hline Pile wall & 25 & 30 & 0.2 \\
Tieback & 78 & 195 & 0.3 \\
\hline
\end{tabular}

to those observed in the excavation case, which increased exponentially as the excavation depth increased. Meanwhile, the results of the elastic method showed different relationships between the wall deformation and excavation depth, especially for $\delta_{m}$. For $\delta_{h}$, that predicted by the elastic method was much larger than those predicted using other methods when the excavation depth was shallower than $18 \mathrm{~m}$. Subsequently, the $\delta_{h}$ value tended to decline as the excavation depth increased and became smaller than those calculated using other methods and observations. For $\delta_{m}$, the design results of the elastic method were larger than the FEM results and the observations, with a maximum gap of $31.8 \mathrm{~mm}$.

Figure 6 shows the comparison between the calculated results and observed values for the last stage, during which the excavation was completed. Figure 6(a) illustrates that 


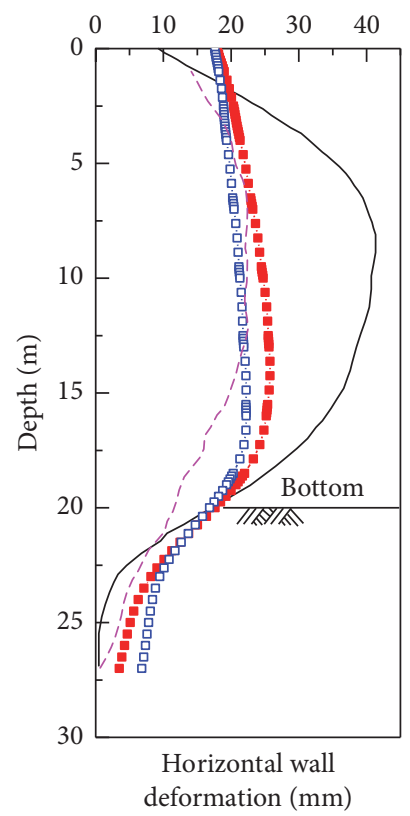

(a)

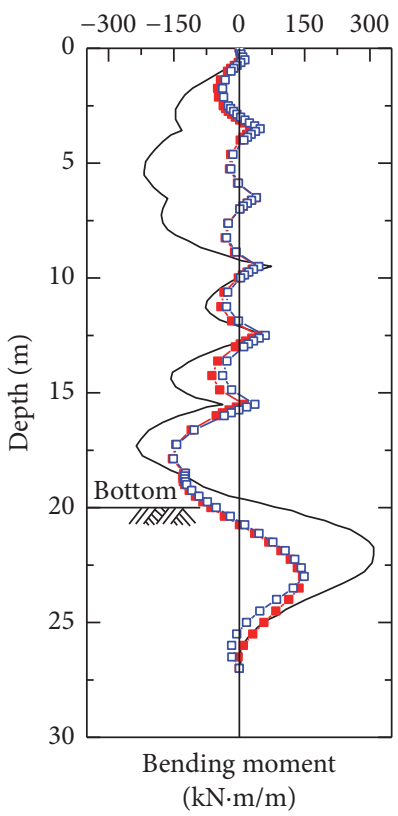

(b)

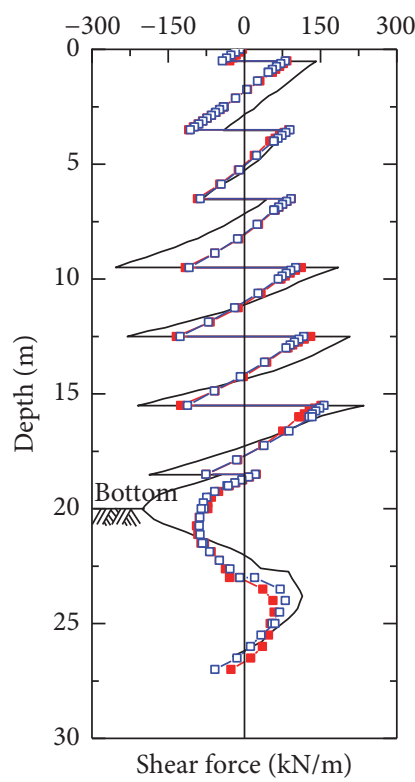

(c)

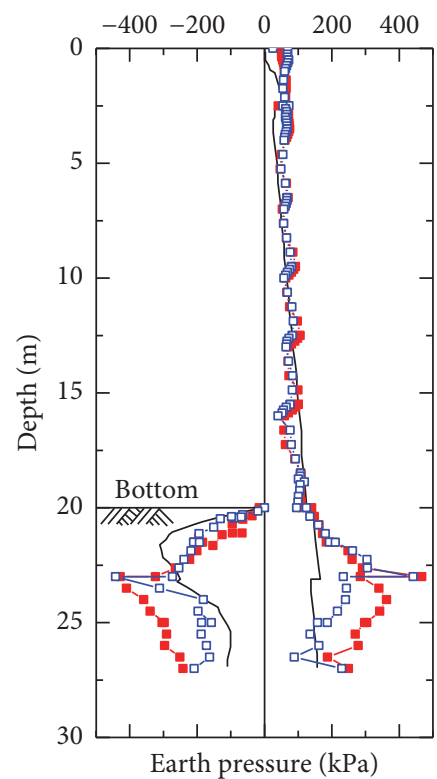

(d)

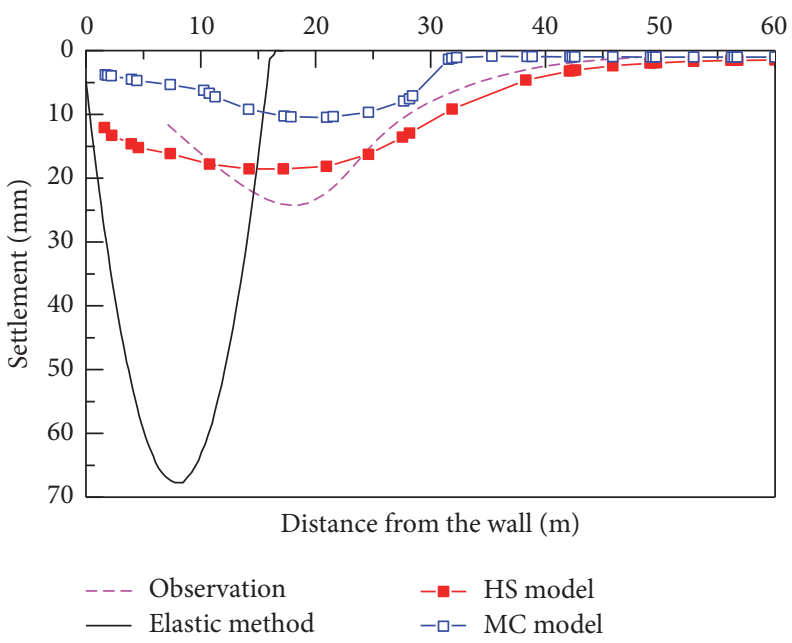

(e)

Figure 6: Comparison of the observed and calculated results using various methods for the deep excavation. (a) Horizontal wall deformation. (b) Bending moment of pile wall. (c) Shear force of pile wall. (d) Earth pressure. (e) Settlement of ground surface.

the horizontal wall deformations calculated using the HS model and the MC model were similar to the observations, with $\delta_{m}$ values of $25.8 \mathrm{~mm}$ and $22.2 \mathrm{~mm}$, respectively. For the elastic method, the horizontal wall deformation was larger than the observations made above the bottom of the excavation but smaller than those made below the bottom of the excavation. The ratio of the $\delta_{m}$ values obtained using the elastic method to those observed in situ was approximately 1.8. Figure 6(a) shows that the $\delta_{m}$ values corresponded to depths of approximately $8 \mathrm{~m}$ for the observations and elastic method results, while the $\delta_{m}$ values corresponded to depths just above the bottom of the excavation for the FEM analysis results.

For the bending moments and shear forces of the pile wall, the calculated results of the FEM using the HS model were in good agreement with those using the MC model, as shown in Figures 6(b) and 6(c), respectively. The distributions of internal forces in the pile wall were improved due to the employment of tieback anchors. The mechanical mode for the pile wall with tiebacks was similar to that of a continuous beam, which reduced the moments and shear forces effectively. The results of the elastic method were similar to but larger than the FEM results. For the FEM models, the maximum bending moment and shear force were $153.5 \mathrm{kN} \cdot \mathrm{m}$ and $151.2 \mathrm{kN}$ per meter along the longitudinal direction, respectively. For the elastic method, the maximum bending moment and shear force were $308.8 \mathrm{kN} \cdot \mathrm{m}$ and $235.0 \mathrm{kN}$, respectively, and the ratios to those obtained via the FEM analysis were 2.0 and 1.6, respectively. 
As shown in Figures 6(a)-6(c), the deformation and the design values of resistance (the bending resistance and the shear resistance) of the pile wall calculated using the elastic method were all larger than the FEM results and the observed values to different degrees. This is mainly because the assumptions of the elastic method, such as the resistance of the soils, the soil-wall interaction, and the stress state of the soils, caused the results to lack accuracy. For example, the earth pressure is closely associated with the soil movement. If the wall has a deformation towards the excavation, the earth pressure behind the wall will decrease and that in front of the wall will increase. The earth pressures for the elastic method were assumed to be the active earth pressure and resistance provided by the Winkler elastic foundation. In addition, the stiffness parameter $k_{s}$, which is determined by the strength parameters of the soils $(c, \varphi)$, the deformation of the wall, and the depths of the soils, represents Young's modulus of the soil body, bringing about a potential deviation of the practical value. The other primary reason is that the results were calculated considering the importance factor $\gamma_{0}$ and the partial factor $\gamma_{F}$, which improved the effects of actions.

To evaluate the accuracy of the earth pressures on the wall predicted by the elastic method, the normal stresses on the wall obtained using the elastic method and the two FEM models are shown in Figure 6(d). Figure 6(d) shows that the earth pressure above the bottom of the excavation calculated using the elastic method closely matches the FEM analysis results. Gaps between various methods occurred below the bottom of the excavation. The maximum earth pressures of the FEM models were $427.9 \mathrm{kPa}$ and $467.0 \mathrm{kPa}$ in front of and behind the wall, respectively. Between depths of $23 \mathrm{~m}$ and $27 \mathrm{~m}$ from the ground surface, the earth pressure calculated using the HS model was larger than that calculated using the MC model. The HS model adopts a hyperbolic stress-strain representation for the soil proposed by Duncan and Chang [39], while the MC model employs a perfectly plastic stressstrain representation. Thus, when the stress states satisfy the Mohr-Coulomb failure criterion, soil hardening occurs for the HS model, while the perfectly plastic state occurs for the MC model. It is believed that the soils were in the hardening state, resulting in the difference in earth pressure between the two constitutive models. The maximum earth pressures calculated using the elastic method were $310.8 \mathrm{kPa}$ and $165.9 \mathrm{kPa}$ in front of and behind the wall, respectively. The friction of the soil-wall interface was neglected in the elastic method. The FEM analysis results showed that the strength of soils around the wall below the excavation was improved due to the friction of the soil-wall interface. As a result, the earth pressure calculated using the elastic method was slightly smaller because friction was not considered.

Figure 6(e) shows the comparison of calculated and observed settlements of the ground surface. The settlement results of the HS model were similar to those observed in situ. The predicted settlements using the MC model were slightly conservative. This result mainly occurred because the MC model adopts the isotropic Young's modulus, does not define the unloading and reloading Young's modulus, $E_{\text {ur }}^{\text {ref }}$, and does not involve a high stiffness modulus at small strain levels.

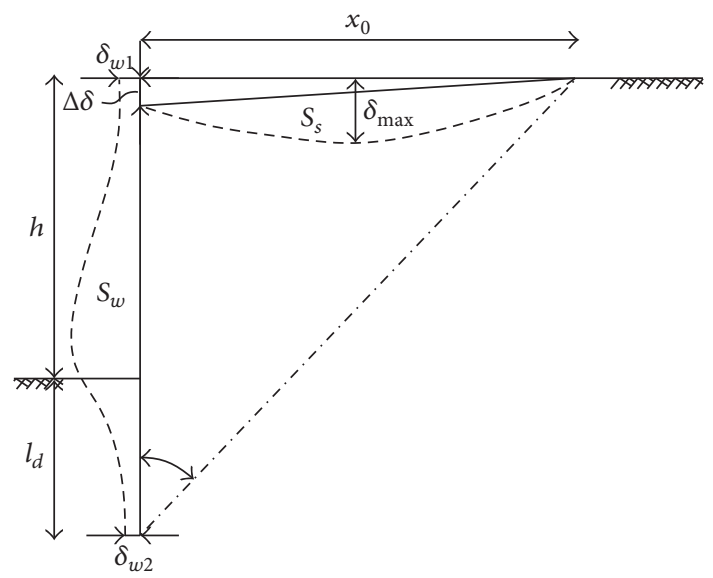

FIGURE 7: Ground surface settlement for the elastic method.

For the elastic method, three ground settlement calculation methods were employed in the current calculation program: triangle method, exponent method, and parabolic method, which are distinguished based on the predicted settlement profile. The parabolic method was selected for this excavation case because the retaining structure was a tieback anchored pile wall [40]. The parabolic method was performed based on the soil loss method, which adopts the basic assumption that the area of the horizontal wall deformation $S_{w}$ is equal to the area of the ground surface settlement $S_{s}$ (see Figure 7). According to this assumption, the scope of the ground surface settlement $x_{0}$ and the maximum settlement $\delta_{\max }$ were determined as follows:

$$
x_{0}=\left(h+l_{d}\right) \cdot \tan \left(\frac{\pi}{4}-\frac{\varphi_{a}}{2}\right),
$$

where $x_{0}$ is the scope of the ground surface settlement; $h$ is the excavation depth; $l_{d}$ is the embedded depth of the retaining structures; and $\varphi_{a}$ is the weighted average of the internal friction angle of the soils covering the wall;

$$
\Delta \delta=\frac{1}{2} \cdot\left(\delta_{w 1}+\delta_{w 2}\right)
$$

where $\Delta \delta$ is the settlement near the wall; $\delta_{w 1}$ is the deformation of the top of the wall; and $\delta_{w 2}$ is the deformation of the bottom of the wall;

$$
\delta_{\max }=\frac{1.6 \cdot S_{w}}{x_{0}}-0.3 \cdot \Delta \delta,
$$

where $\delta_{\max }$ is the maximum settlement and $S_{w}$ is the area of the horizontal wall deformation. As shown in Figure 6(e), the $\delta_{\max }$ value calculated using the elastic method was $67.7 \mathrm{~mm}$, which was approximately 2.7 times that observed. The significant deviation between the results of the elastic method and the in situ observations was primarily contributed by the underestimation of the $x_{0}$ value ( 0.4 times the observed $x_{0}$ value). Because of the reinforcement of the tiebacks, the strength of the soils behind the wall was improved, leading to the potential slip surface moving further away from the excavation and the expansion of $x_{0}$. 


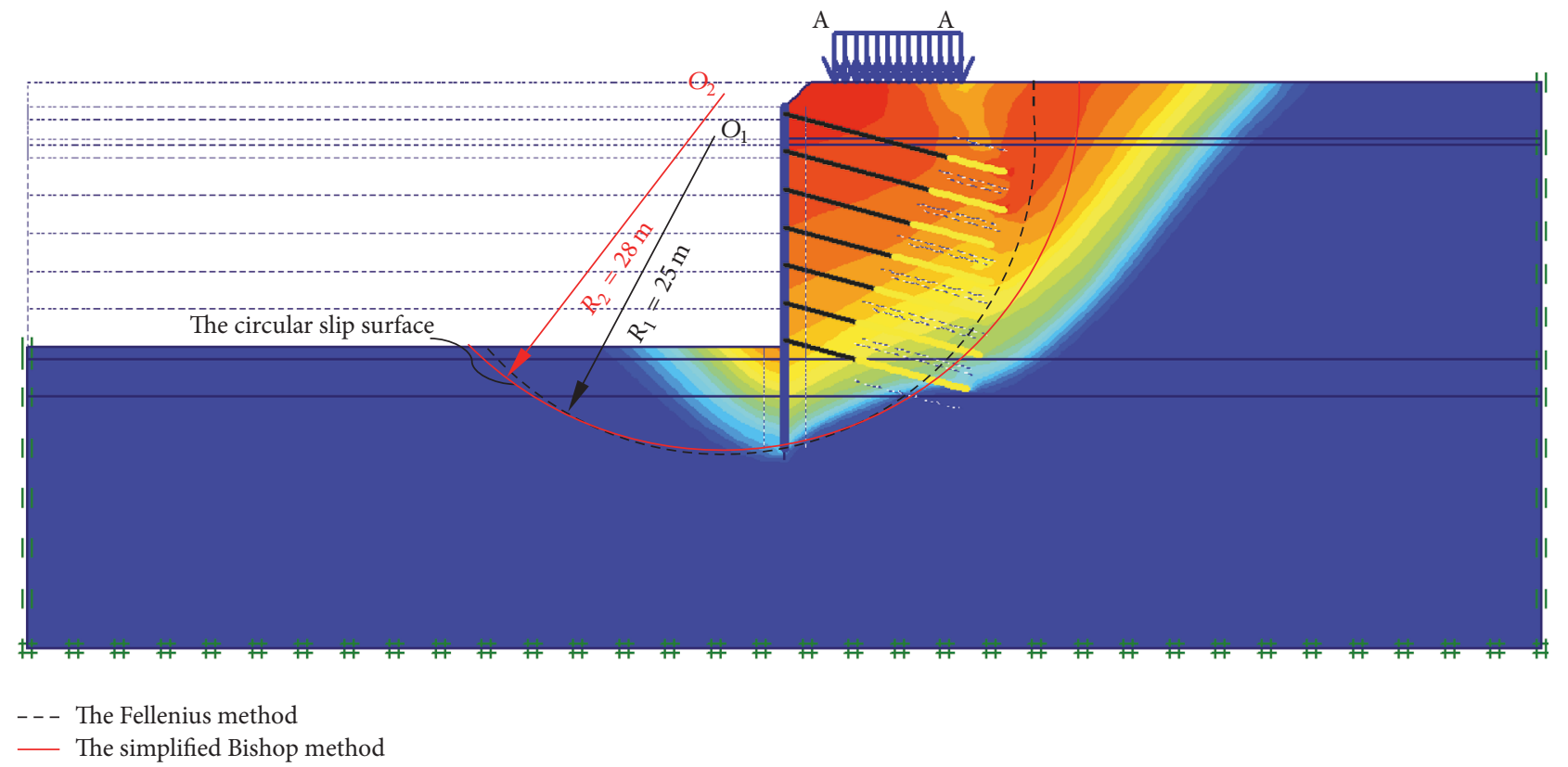

FIGURE 8: Slip surfaces of the excavation based on various calculation methods.

According to the comparison of the results of the elastic method, the FEM models, and the observed data, the elastic method overestimated the primary design parameters, such as the deformations and internal forces of the retaining structure and the settlement of the ground surface. This mainly occurred because of the limitation of the calculation method and the influence of the partial factors. The overestimation of the results can ensure the security of design in practice. However, an overly high cost and an unnecessary waste of materials may occur.

In the design process of a deep excavation, verifications of not only the resistance from the retaining structure but also the stabilities of the excavation and retaining structures are necessary. The limit equilibrium methods are frequently used by geotechnical engineers to study the stability problems of both slopes and deep excavations [41]. The method of slices, one type of limit equilibrium method [42, 43], has become a common method due to its ability to accommodate complex geometrics and variable soil and ground water conditions [44]. Several methods of slices have been developed; two of the most commonly used methods, which are recommend by JGJ 120-2012, that is, the Fellenius method (the conventional method of slices) and the simplified Bishop method, are applied in the Deep Excavation program. In this excavation case, the safety coefficients calculated using the Fellenius method and the simplified Bishop method were 1.71 and 2.15, respectively, which both satisfied the requirement of $K \geq$ 1.35 (for Grade 1). The deviation between the two methods was attributed to the assumption used for the evaluation of the normal interslice force. The Fellenius method is more conservative due to the neglect of the normal interslice force [45].

For the FEM model, the strength reduction method is commonly applied in stability analysis to calculate the safety coefficient. In the Plaxis program, the strength parameters, $c$ and $\varphi$, are reduced by small amounts, using a Phi- $c$ reduction analysis program embedded in Plaxis, to reach the ultimate state of soils. The safety coefficient is equal to the reduction ratio that satisfies the following equation:

$$
K=F_{R}=\frac{\tan \varphi_{0}}{\tan \varphi_{r}}=\frac{c_{0}}{c_{r}},
$$

where $F_{R}$ is the reduction ratio; $\varphi_{0}$ and $c_{0}$ are the initial strength parameters of soils; and $\varphi_{r}$ and $c_{r}$ are the reduced strength parameters of soils. The $K$ value in the excavation case was calculated via reduction analysis to be 1.71 , which was equal to the result of the Fellenius method. Figure 8 shows the total deformation contours of the soil body. As shown in Figure 8, the shape of the slip surface was not a typical cambered surface or plane surface. The integrity and capacity of the soil body behind the wall were improved because of the reinforcement of prestressed tieback anchors, which made the sliding scope farther from the wall. The slip surface developed through the bottom of the wall and the end of the 7 th row of tieback anchors and then reached the ground surface with an angle of approximately $40^{\circ}$ with respect to the vertical direction. To compare with the results of the elastic method and the finite element method in terms of the stability analysis of excavation, the potential slip surfaces predicted by the two methods of slices are also illustrated in Figure 8 . The radiuses of the circular slip surfaces assumed in the Fellenius method and the simplified Bishop method were $28 \mathrm{~m}$ and $25 \mathrm{~m}$, respectively. Compared with the potential slip surface obtained using the FEM model, the scope of the most dangerous slip surfaces calculated was wider in front of the wall but narrower behind it. For tieback anchored pile wall retained excavation, the deviation of the stability analysis was significant between the limit equilibrium method and the strength reduction method. 
In addition to the stability analysis of excavation, the verifications of resistance to overturning and basal stability are also important for an excavation design. For a multirow tieback anchored pile wall, the prestressed tieback anchors can effectively restrain the overturning failure, causing the rotational failure and the basal stability failure to occur with higher probability compared to the overturning failure. Due to this fact, the verification of resistance to overturning is not required according to JGJ 120-2012.

Several limit equilibrium methods are available for evaluating the basal stability of excavations. The calculated safety factors vary with the different methods [46, 47]. The safety factor of basal stability is predicted using the methods proposed by Prandtl recommended by JGJ 120-2012. Compared with the common methods proposed by Terzaghi [17] and Bjerrum and Eide [48], the Prandtl stability analysis method is slightly conservative [49], which means that it is safer for the design. The safety factor against basal instability is expressed as follows:

$$
\begin{aligned}
& K_{b}=\frac{\gamma_{m 2} l_{d} N_{q}+c N_{c}}{\gamma_{m 1}\left(h+l_{d}\right)+q_{0}}, \\
& N_{q}=\tan ^{2}\left(45+\frac{\varphi}{2}\right) e^{\pi \tan \varphi}, \\
& N_{c}=\frac{\left(N_{q}-1\right)}{\tan \varphi},
\end{aligned}
$$

where $K_{b}$ is the safety factor against basal instability; $\gamma_{m 1}$ and $\gamma_{m 2}$ are the natural unit weights of soils outside and inside the excavation above the bottom of the wall, respectively; $q_{0}$ is the surcharge on the ground surface; and $N_{c}$ and $N_{q}$ are bearing capacity factors. According to the result of the calculation, the safety factor of basal stability was approximately 11.7, which satisfied the requirement of $K_{b} \geq 1.8$.

4.2. Comparison of Design Approaches in China and Europe. In Europe, the Structural Eurocode program comprises ten standards (EN1990 Eurocode-EN1999 Eurocode 9), of which Eurocode 7, Geotechnical Design, provides guidance and rules for the geotechnical design of civil engineering works [50]. Eurocode 7 includes two parts: EN 1997-1: General rules and EN 1997-2: Ground investigation and testing [51]. For the design of a deep excavation, EN 1997-1 contains primary design approaches and rules; thus, it was selected to compare with JGJ 120-2012. The current version of EN 1997-1 (2004) supersedes ENV 1997-1: 1994.

4.2.1. Common Rules between Chinese and European Design Standards. Regarding the geotechnical designs for deep excavation, the Chinese standard and European standard have many rules in common. For both the Chinese standard and European standard, verification is a critical procedure during the design process and includes the verification of resistance to internal failure for structural elements, such as verification of the bending resistance and shear resistance, the verification of resistance to overturning, and the verification of the overall stability of excavation. In addition, the design theories based on the limit states, including the ULS and SLS, are described
TABLE 6: The partial factors of actions and effects of actions.

\begin{tabular}{lccc}
\hline \multirow{2}{*}{ Action } & & Set \\
& & A1 & A2 \\
\hline \multirow{2}{*}{ Permanent } & Unfavourable & 1.35 & 1.0 \\
& Favourable & 1.0 & 1.0 \\
Variable & Unfavourable & 1.5 & 1.3 \\
& Favourable & 0 & 0 \\
\hline
\end{tabular}

in two standards, where a slight difference exists regarding the definition of the SLS. The classical soil mechanics theory is applied to evaluate the geotechnical actions and the resistance of soils for both the Chinese and European standards.

4.2.2. Differences between Chinese and European Design Standards. There are lots of differences between the Chinese and European design standards in terms of the design focus, partial factors, design approaches, and so on. For the European code EN 1997-1, the primary design theory is the reliability theory based on the limit states, the requirements of which are defined to satisfy the following inequality:

$$
S_{d} \leq R_{d}
$$

Compared with inequality (1), inequality (13) of the European code does not consider the factor $\gamma_{0}$, which represents the importance of a geotechnical work. For the Chinese code JGJ 120-2012, three design theories, that is, the reliability theory based on the limit states, the design theory based on the allowable bearing capacity, and the design theory based on the safety factors, are used for various aspects of design. The reliability theory based on the limit states is mainly applied in the evaluation of the actions and effects of actions, considering various partial factors. The design theory based on the allowable bearing capacity is applied in the evaluation of the soil bearing capacity, which is determined based on experience. The design theory based on the safety factors is primarily used in the verification of the stabilities of structures and the ground and should satisfy inequality (3).

In terms of the partial factors, the design standards of China and Europe for deep excavations have significant differences. For the European code, the partial factors are assigned with different values for the actions, soil parameters (material properties), and resistances. For example, the partial factors of actions are distinguished according to the various action conditions, that is, permanent actions or variable actions and favorable actions or unfavorable actions (see Table 6). For the verification of structural (STR) and geotechnical (GEO) limit states, the recommended values of partial factors are given in Table 5 according to $\mathrm{EN}$ 1997-1. For the Chinese code, the partial factors of actions and effects of actions, which are represented by $\gamma_{F}$, the comprehensive partial factor, are uniform. For the partial factors of geotechnical parameters and resistances, the values of the partial factors are considered to be equal to 1.0.

The concept of the partial factor was developed from the safety factor in stability estimates which was proposed by Coulomb [52] in 1773. The global or total safety factors were 


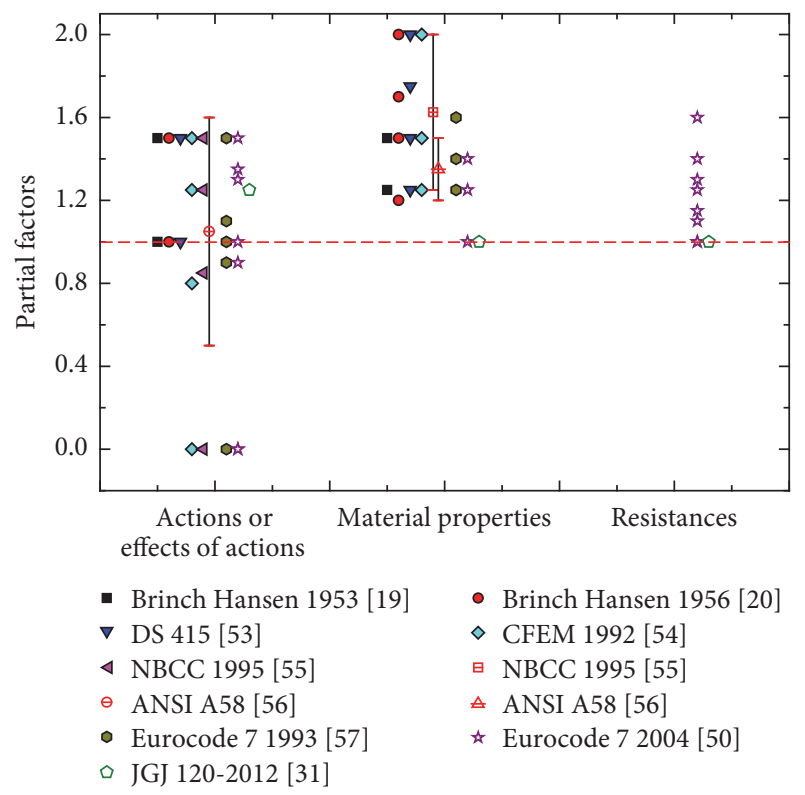

FIGURE 9: Various partial factors for actions, material properties, and resistance. DS 415: Code of Practice for Foundation Engineering; CFEM: Canadian Foundation Engineering Manual; NBCC: National Building Code of Canada; ANSI: American National Standard.

widely used in geotechnical design in the worldwide during the 18th century. However, a total safety factor is shown to be insufficient for geotechnical optimizing designs and cost control. Separate safety factors were introduced on the soil strength parameters by Taylor [18] and were developed by many researchers and engineers. Various partial factors from researchers and different design standards are shown in Figure 9. The short line with a symbol in the middle represents the values of partial factors range from the top end to the bottom end of the line. As shown in Figure 9, two types of partial factors proposed by Brinch Hansen $[19,20]$ in the 1950s are similar to the partial factors recommended by various design standards [53]. For partial factors used for actions and effects of actions, the partial factor values are limited to smaller than 1.5. It is of interest to note that part of partial factors provided by three North American design standards (CFEM [54], NBCC [55], and ANSI [56]) and Eurocode $7[50,57]$ are smaller than 1.0. These partial factors are applied when the actions or effects of actions are favorable for the structure. The partial factor values for the material properties range from 2.0 to 1.0. For the American standard and European standard, the partial factor values for the material properties show a smaller range variation, which changes from 1.6 to 1.0. The partial factors for the resistances provided by European standard and Chinese standard are listed in Figure 9.

Compared with the partial factors in European and Chinese standards, the partial factors used in the European design standard are more detailed than those used in the Chinese design standard. Moreover, the reliability theories of the actions, materials, and resistances are relatively clear for the European design standard.

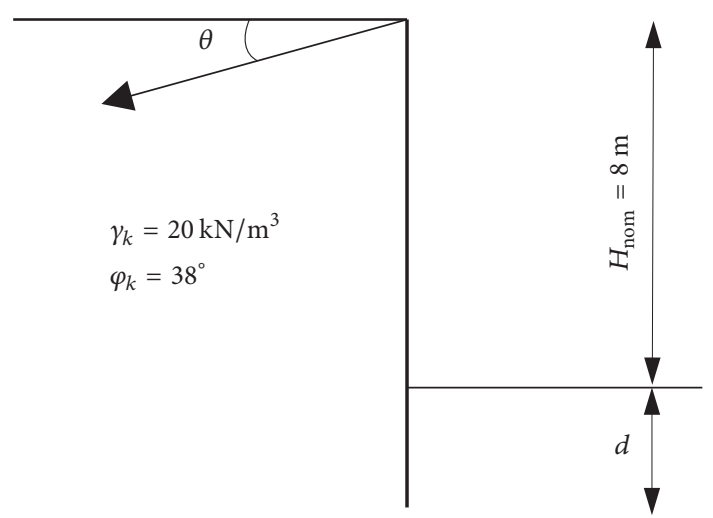

FIGURE 10: Excavation retained by an anchored sheet pile wall.

In terms of the design approaches, when considering the limit states of damage or excessive deformations of structures or sections of the ground (STR and GEO) in persistent and transient situations, three design approaches can be selected from the European design standard, which serve as the critical part of EN 1997-1 and constitute the primary difference with respect to the Chinese design standard. The three design approaches, DA1, DA2, and DA3, differ in the way in which they distribute partial factors among actions, material properties, and resistances.

In Table 7, the partial factors are grouped in sets denoted by $\mathrm{A}$ (for actions or effects of actions), M (for material properties), and $\mathrm{R}$ (for resistances), which are selected according to the design approach used, and + means "to be combined with." For DAl, if one of the two combinations governs the design, the other combination does not need to be calculated.

4.2.3. Design Example. A sheet pile wall design example was considered using the European and Chinese design standards to compare the design results of the two codes [58]. Figure 10 shows the profile of an excavation retained by an anchored sheet pile wall. The nominal excavation depth $H_{\text {nom }}$ is $8 \mathrm{~m}$ from the ground surface. Dense sand with a characteristic unit weight $\gamma_{k}=20 \mathrm{kN} / \mathrm{m}^{3}$ and drained friction angle $\varphi_{k}=$ $38^{\circ}$ surrounds the excavation site. The characteristic value of the constant-volume angle of soils is assumed to be $\varphi_{c v, k}$ $=30^{\circ}$. A tieback anchor is installed with a horizontal angle $\theta=30^{\circ}$ and an ultimate design resistance $R_{a, d}=130 \mathrm{kN} / \mathrm{m}$. The sheet pile is assumed to be a $Z$-section pile with a flange thickness $t_{f}=8.5 \mathrm{~mm}$, web thickness $t_{w}=8.5 \mathrm{~mm}$, section height $h=302 \mathrm{~mm}$, pile space $b=670 \mathrm{~mm}$, elastic section modulus $W_{e l}=1400 \mathrm{~cm}^{3} / \mathrm{m}$, and characteristic yield strength $f_{y k}=355 \mathrm{MPa}$. The ground is dry.

(1) European Code (EN 1997-1). In EN 1997-1, to allow an unplanned excavation for ULS verification, the design retained height of the pile wall is

$$
H_{d}=H_{\mathrm{nom}}+\min \left(0.1 H_{\mathrm{nom}} ; 0.5 \mathrm{~m}\right)=8.5 \mathrm{~m} .
$$


TABLE 7: The partial factor combinations for three design approaches.

\begin{tabular}{|c|c|c|}
\hline Design approach & \multicolumn{2}{|c|}{ Combination } \\
\hline \multirow{4}{*}{ DA1 } & \multirow{2}{*}{ Except for the piles and anchors } & Combination 1: A1“+”M1“+”R1 \\
\hline & & Combination 2: $\mathrm{A} 2$ “+”M2“+”R1 \\
\hline & \multirow{2}{*}{ For the piles and anchors } & Combination 1: A1“+"M1“+”R1 \\
\hline & & Combination 2: A2“+”(M1 or M2)“+”R4 \\
\hline DA2 & \multicolumn{2}{|c|}{ 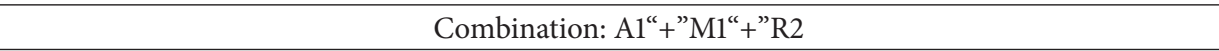 } \\
\hline DA3 & \multicolumn{2}{|c|}{ Combination: (A1 or A2) “+”M2“+”R3 } \\
\hline
\end{tabular}

TABLE 8: The partial factor used in the European code.

\begin{tabular}{|c|c|c|c|c|c|c|c|c|c|c|c|c|c|c|c|}
\hline \multirow{2}{*}{\multicolumn{2}{|c|}{ Parameter }} & \multirow{2}{*}{ Symbol } & \multicolumn{3}{|c|}{ DA1-1 } & \multicolumn{3}{|c|}{ DA1-2 } & \multicolumn{3}{|c|}{ DA2 } & \multicolumn{4}{|c|}{ DA3 } \\
\hline & & & A1 & M1 & $\mathrm{R} 1$ & $\mathrm{~A} 2$ & M2 & $\mathrm{R} 1$ & $\mathrm{~A} 1$ & M1 & $\mathrm{R} 2$ & $\mathrm{~A} 1$ & $\mathrm{~A} 2$ & M2 & R3 \\
\hline \multirow{2}{*}{ Permanent action } & Unfavourable & $\gamma_{G}$ & 1.35 & & & 1.0 & & & 1.35 & & & 1.35 & 1.0 & & \\
\hline & Favourable & $\gamma_{G, \mathrm{fav}}$ & 1.0 & & & & & & 1.0 & & & & & & \\
\hline \multirow{2}{*}{ Variable action } & Unfavourable & $\gamma_{\mathrm{Q}}$ & 1.5 & & & 1.3 & & & 1.5 & & & 1.5 & 1.3 & & \\
\hline & Favourable & - & 0 & & & 0 & & & 0 & & & 0 & & & \\
\hline \multicolumn{2}{|c|}{ Shearing resistance $(\tan \varphi)$} & $\gamma_{\varphi}$ & & 1.0 & & & 1.25 & & & 1.0 & & & & 1.25 & \\
\hline \multicolumn{2}{|c|}{ Unit weight $(\gamma)$} & $\gamma_{\gamma}$ & & & & & 1.0 & & & & & & & 1.0 & \\
\hline \multicolumn{2}{|c|}{ Bearing resistance $(R v)$} & $\gamma_{R v}$ & & & & & & & & & 1.4 & & & & \\
\hline \multicolumn{2}{|c|}{ Sliding resistance $(R h)$} & $\gamma_{R h}$ & & & 1.0 & & & 1.0 & & & 1.1 & & & & 1.0 \\
\hline \multicolumn{2}{|c|}{ Earth resistance $(R e)$} & $\gamma_{R e}$ & & & & & & & & & 1.4 & & & & \\
\hline
\end{tabular}

The three design approaches are used in the design, the partial factors used for which are listed in Table 8 . The soil parameters are calculated as follows:

$$
\begin{aligned}
\varphi_{d} & =\arctan \left(\frac{\tan \left(\varphi_{k}\right)}{\gamma_{\varphi}}\right), \\
\varphi_{c v, d} & =\min \left(\varphi_{d}, \varphi_{c v, k}\right), \\
\delta_{d} & =k \varphi_{c v, d},
\end{aligned}
$$

where $\varphi_{d}$ is the design value of the friction value; $\varphi_{c v, d}$ is the design value of the constant-volume angle of soils; $\delta_{d}$ is the friction angle of the soil-wall interface; and $k$ is the reduction factor of the constant-volume angle of soils. According to the European code, the recommended earth pressure coefficients (active earth pressure coefficient $K_{a, h}$ and passive earth pressure coefficient $K_{p, h}$ ), which satisfy the functions of $\varphi_{d}$ and $\delta_{d} / \varphi_{d}$, are from Annex C of EN 1997-1. The actions are calculated as follows:

$$
\begin{aligned}
& \gamma_{\mathrm{Q} / G}=\frac{\gamma_{\mathrm{Q}}}{\gamma_{G}} \\
& M_{E d, d s t} \\
& \quad=\gamma_{G} K_{a, h}\left(\frac{1}{3} \gamma_{K}\left(H_{d}+d\right)^{3}+\frac{1}{2} \gamma_{\mathrm{Q} / G} q_{K}\left(H_{d}+d\right)^{2}\right), \\
& M_{E d, s t b}=\frac{\gamma_{G, f a v} K_{p, h}\left((1 / 2) \gamma_{K} d^{2}\left(H_{d}+(2 / 3) d\right)\right)}{\gamma_{\mathrm{Re}}}, \\
& P_{a, E d}=\gamma_{G} K_{a, h}\left(\frac{1}{2} \gamma_{K}\left(H_{d}+d\right)^{2}+\gamma_{\mathrm{Q} / G} q_{K}\left(H_{d}+d\right)\right),
\end{aligned}
$$

$$
\begin{aligned}
& P_{p, E d}=\frac{\gamma_{G, f a v} K_{p, h}\left((1 / 2) \gamma_{K} d^{2}\right)}{\gamma_{\mathrm{Re}}}, \\
& P_{E d}=P_{a, E d}-P_{p, E d}, \\
& F_{a, E d}=\frac{\max \left(P_{E d i}\right)}{\cos (\theta)}, \\
& z=\sqrt{\frac{P_{E d}}{\gamma_{G} K_{a, h}(1 / 2) \gamma_{K}}}, \\
& M_{E d}=P_{E d} z-\gamma_{G} K_{a, h}\left(\frac{1}{6} \gamma_{K} z^{3}+\frac{1}{2} \gamma_{\mathrm{Q} / G} q_{K} z^{2}\right),
\end{aligned}
$$

where $\gamma_{\mathrm{Q} / G}$ is the ratio of variable to permanent partial factors; $M_{E d, d s t}$ is the rotating moment around the anchor; $M_{E d, s t b}$ is the resisting moment around the anchor; $d$ is the depth of embedment of the pile wall; $q_{K}$ is the surcharge on the ground surface, which is assumed to be $0 \mathrm{kPa}$ in this case; $P_{a, E d}$ is the active thrust on the pile wall; $P_{p, E d}$ is the passive thrust on the pile wall; $P_{E d}$ is the net thrust; $F_{a, E d}$ is the axial force of the tieback anchor; $z$ is the depth of the zero shear force in the pile wall; and $M_{E d}$ is the maximum moment of the pile wall. The resistances are verified as follows:

$$
\begin{aligned}
M_{c, R d} & =\frac{W_{e l} f_{y k}}{\gamma_{M 0} \gamma_{R v}}, \\
A_{V} & =\frac{t_{w}\left(h-t_{f}\right)}{b}, \\
V_{p l, R d} & =\frac{A_{V} f_{y k}}{\sqrt{3} \gamma_{M 0} \gamma_{R v}},
\end{aligned}
$$


TABLE 9: The design results for the sheet pile wall using European code EN 1997-1.

\begin{tabular}{|c|c|c|c|c|c|}
\hline & Sumbol & & & DA2 & DA3 \\
\hline & syintur & DA1-1 & DA1-2 & DH2 & DHJ \\
\hline & $\varphi_{d}\left(^{\circ}\right)$ & 38 & 32 & 38 & 32 \\
\hline & $\varphi_{c v, d}\left({ }^{\circ}\right)$ & & & 30 & 30 \\
\hline Soil parameters & $\delta_{d}\left({ }^{\circ}\right)$ & & & 20 & 20 \\
\hline & $K_{a, h}$ & 0.21 & 0.26 & 0.21 & 0.26 \\
\hline & $K_{p, h}$ & 7.39 & 5.18 & 7.39 & 5.18 \\
\hline & $d(\mathrm{~m})$ & 1.11 & 2.01 & 2.05 & 2.05 \\
\hline & $M_{E d, d s t}(\mathrm{kN} \cdot \mathrm{m} / \mathrm{m})$ & 1790 & 2040 & 2180 & 2035 \\
\hline & $M_{E d, s t b}(\mathrm{kN} \cdot \mathrm{m} / \mathrm{m})$ & 1789 & 2061 & 2188 & 2148 \\
\hline & $P_{a, E d}(\mathrm{kN} / \mathrm{m})$ & 272 & 291 & 310 & 289 \\
\hline Actions & $P_{p, E d}(\mathrm{kN} / \mathrm{m})$ & 190 & 209 & 222 & 218 \\
\hline Actions & $P_{E d}(\mathrm{kN} / \mathrm{m})$ & 81.9 & 81.7 & 88.2 & 71 \\
\hline & $F_{a, E d}(\mathrm{kN} / \mathrm{m})$ & & & 101.9 & 82.0 \\
\hline & $z(\mathrm{~m})$ & 5.42 & 5.57 & 5.63 & 5.23 \\
\hline & $M_{E d}(\mathrm{kN} \cdot \mathrm{m} / \mathrm{m})$ & 296 & 303 & 331 & 247 \\
\hline & $V_{E d}(\mathrm{kN} / \mathrm{m})$ & & & 88.2 & 71 \\
\hline Resistance to overturning & Overdesign factor & 1 & 1.01 & 1 & 1.06 \\
\hline Bending resistance & $M_{c, R d}(\mathrm{kN} \cdot \mathrm{m} / \mathrm{m})$ & & & 355 & 497 \\
\hline Detiluntg tesistante & Overdesign factor & & & 1.07 & 2.01 \\
\hline Shear resistance & $V_{p l, R d}(\mathrm{kN} \cdot \mathrm{m})$ & & & 545.1 & 763.2 \\
\hline & Overdesign factor & & & 6.18 & 10.75 \\
\hline Anchor pullout capacity & Overdesign factor & & & 1.16 & 1.59 \\
\hline
\end{tabular}

where $M_{c, R d}$ is the design bending resistance of the sheet pile section; $\gamma_{M 0}$ is the partial factor of steel's yield strength; $A_{V}$ is the shear area; and $V_{p l, R d}$ is the design resistance of the sheet pile. The design results of the three design approaches are listed in Table 9.

(2) Chinese Code (JGJ 120-2012). In JGJ 120-2012, two design methods, the elastic method and the classical method, are recommended for the anchored retaining structure. Because this anchored sheet pile wall is not complex, the classical method is capable of designing the retaining structure. The embedment of the pile wall $d$ is determined using the following inequality, which ensures resistance to overturning:

$$
\begin{aligned}
\frac{M_{E d, s t b}}{M_{E d, d s t}} & =\frac{K_{p, h}\left((1 / 2) \gamma_{K} d^{2}\left(H_{\mathrm{nom}}+(2 / 3) d\right)\right)}{K_{a, h}\left((1 / 3) \gamma_{K}\left(H_{\mathrm{nom}}+d\right)^{3}\right)} \\
& \geq K_{\mathrm{em}} \\
K_{a, h} & =\tan ^{2}\left(45^{\circ}-\frac{\varphi_{k}}{2}\right), \\
K_{p, h} & =\tan ^{2}\left(45^{\circ}+\frac{\varphi_{k}}{2}\right),
\end{aligned}
$$

where $K_{\mathrm{em}}$ is the safety factor of the embedded stability, which is selected to be 1.25 according to JGJ 120-2012. Hence, the $d$ value is assumed to be $2.4 \mathrm{~m}$ ( $d$ should not be shorter than $\left.0.3 H_{\text {nom }}\right) . F_{a, E d}$ and $M_{E d}$ are calculated using (19)-(24), for which the partial factors are assumed to be equal to 1.0. The verification of resistance should satisfy (1) and (2).
TABLE 10: The design results for the sheet pile wall using Chinese code JGJ 120-2012.

\begin{tabular}{lcc}
\hline Symbol & $\begin{array}{c}\text { Classical } \\
\text { method }\end{array}$ & Leading Software \\
\hline$K_{a, h}$ & 0.24 & 0.24 \\
$K_{p, h}$ & 4.20 & 4.20 \\
$d(\mathrm{~m})$ & 2.4 & 2.4 \\
$M_{E d}(\mathrm{kN} \cdot \mathrm{m} / \mathrm{m})$ & 249.4 & 281.9 \\
$\begin{array}{l}\text { Bending resistance } \\
\text { overdesign factor }\end{array}$ & 1.99 & 1.76 \\
$V_{E d}(\mathrm{kN} / \mathrm{m})$ & 80.2 & 127.2 \\
$\begin{array}{l}\text { Shear resistance overdesign } \\
\text { factor }\end{array}$ & 9.52 & 6.00 \\
$F_{a, E d}(\mathrm{kN} / \mathrm{m})$ & 92.8 & 100.5 \\
$\begin{array}{l}\text { Anchor pullout capacity } \\
\text { overdesign factor }\end{array}$ & 1.40 & 1.29 \\
\hline
\end{tabular}

The design results are shown in Table 10. The pile wall was also calculated using the Deep Excavation software for comparison.

The comparison between the Chinese and European design approaches showed that the design theories used in the two codes are similar, with the exception of a major difference in terms of the definitions of partial factors. In the European code, the partial factors for actions, materials, and resistances are defined separately. However, in the Chinese code, the comprehensive partial factor $\gamma_{F}$ and the factor depending on 


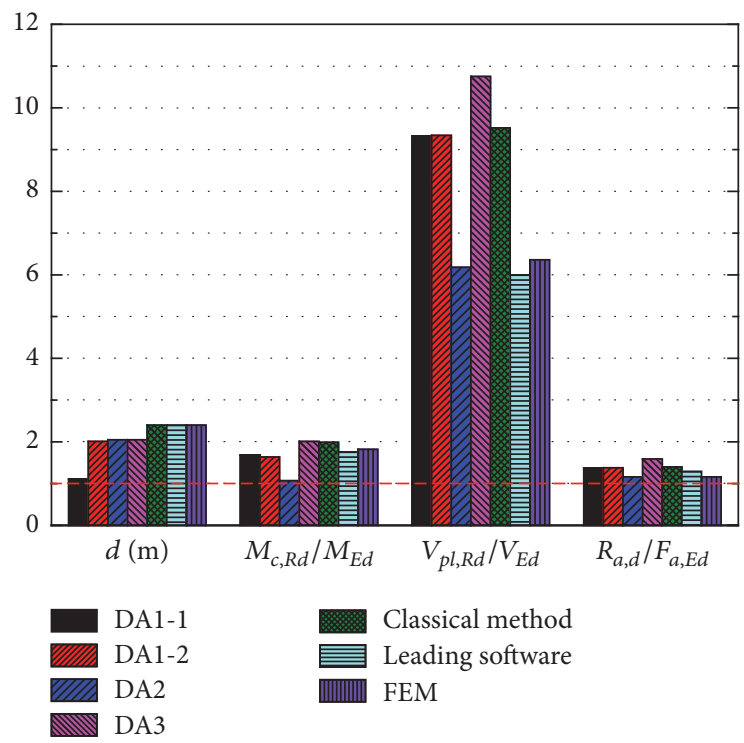

FIGURE 11: Design results obtained using various design approaches.

the importance of the retaining structure $\gamma_{0}$ maintain the safety and redundancy of the retaining structure.

The design results obtained using the various design approaches are illustrated in the column graph of Figure 11. A FEM model was also established by Plaxis as a reference to verify the accuracy of the design results of the European code and Chinese code. The geometry and parameters of the numerical model were selected as above. In addition, because the deformations of soils and the interactions between soils and structures were considered, the stiffness parameters of the soils were assumed to be $E_{50}^{\text {ref }}=E_{\text {oed }}^{\text {ref }}=100 \mathrm{MPa}$ and $E_{\mathrm{ur}}^{\mathrm{ref}}=300 \mathrm{MPa}$, and the strength parameter $R_{\text {inter }}$ was set to 0.67 . The fixed length and free length of the tieback anchor were set equal to $4.5 \mathrm{~m}$ and $6 \mathrm{~m}$, respectively, according to the design results of Deep Excavation.

As shown in Figure 11, the overdesign factors of shear resistance $\left(V_{p l, R d} / V_{E d}\right)$ were relatively large (6.0-11.0), while the overdesign factors of anchor pullout capacity $\left(R_{a, d} / F_{a, E d}\right)$ were slightly larger than 1.0. Hence, the failure of a tieback anchored pile wall is commonly dominated by its bending capacity and anchor pullout capacity. Figure 11 shows that the values of $d, M_{c, R d} / M_{E d}$, and $R_{a, d} / F_{a, E d}$ for the various design approaches only vary slightly, except for a large variation of $V_{p l, R d} / V_{E d}$. Compared with the results of the FEM model, the design results of the Deep Excavation software are shown to be the closest in terms of the three overdesign factors.

The overdesign factors represent the gap between the actions calculated and the resistance of structures. The larger the overdesign factors are, the more insecure the design results are. For the two design approaches of the Chinese code, the Deep Excavation software was more conservative than the classical method, especially for the shear resistance. For the three design approaches of the European code, DA2 was the most conservative one because the partial factors of the resistance were used in DA2, while DA3 was the most insecure among the three approaches.

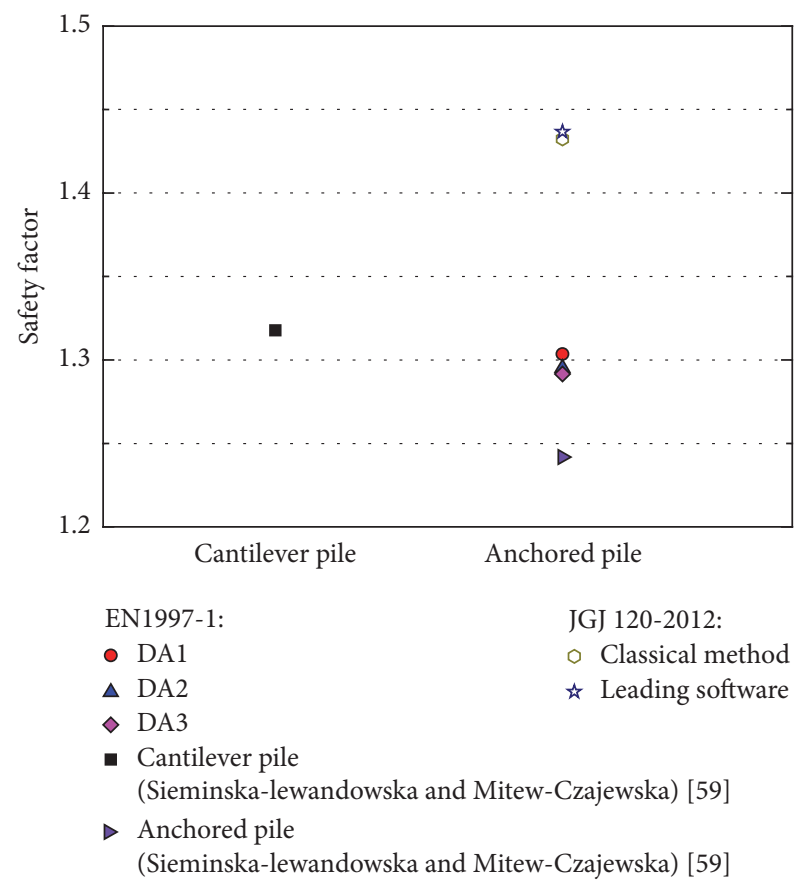

FIGURE 12: Safety factors of various design results.

Actually, a total safety factor can reflect the security of an excavation or a slope to some extent. Therefore, the strength reduction method was selected using the Plaxis program to obtain the safety factors of the design results. Seven finite element models were established based on the design results. Figure 12 shows the safety factors of design results calculated using the strength reduction method. The design results calculated by Sieminska-lewandowska and Mitew-Czajewska [59] in accordance with EN 1997-1 were selected as a comparison. As shown in Figure 12, the safety factors of the design example using DA1, DA2, and DA3 showed a small deviation, which were approximately 1.30. The maximum safety factors of design result according to EN 1997-1 were 1.32. Compared with the European standard, the design results provided higher security using the Chinese standard. The safety factors of the design example using JGJ 120-2012 were approximately 1.43. Further studies about the safety factors of various design results are needed because the strength of retaining structures does not reduce in the process of strength reduction method.

\section{Monitoring and Construction Methods of Deep Excavation}

In construction, uncertainties, such as uncertain geological conditions, uncertainties in laboratory and in situ tests, and uncertain construction quality, introduce several risks to a deep excavation. Thus, knowing how to reduce the risk during excavation construction is critical to ensure the safety of the excavation and its surroundings. Routine programs of inspection and monitoring can provide early warnings regarding the need for precautionary or remedial measures to safeguard the stability of an excavation. 


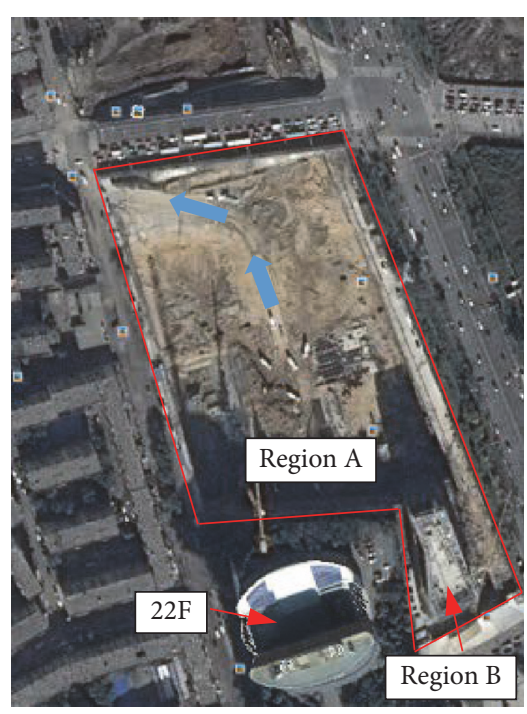

(a)

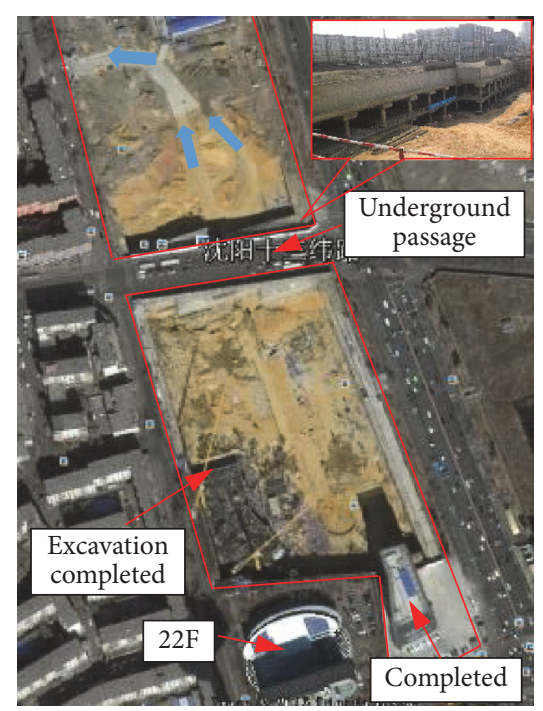

(b)

Figure 13: Planar graph of the excavation during different construction periods. (a) 5th excavation (-15.3 m). (b) 8 th excavation (-22 m).

5.1. Construction Methods of the Deep Excavation. The deep excavation case history was located in the center district of the city, where a busy street and dense constructions exist in close proximity (see Figure 13). The pile wall was constructed before the soil was excavated, and the tieback anchors were installed as the soil was excavated. The soils of the excavation were excavated using the island excavation method, which means that the soils near the pile wall were cut first, thus leaving only the center part of the soils. As a consequence, the tieback anchors could be installed early, and the center part of the soils experienced improved excavation stability. In addition, the zone excavation method [60] was applied to this excavation. Because of the corner effect of the pile wall, the excavation experienced less deformation of the retaining structure or ground settlement at or around the corners. Deformation on the shorter side of the excavation was less than that on the longer side. Hence, Region A was divided into two small-sized excavations (north excavation part and south excavation part), which were constructed at the same time. The soils between the two parts were left with a width of $40 \mathrm{~m}$ until installation of the 4 th row of tieback anchors was completed. Then, the soil partition was removed after the 4 th excavation $(-12.3 \mathrm{~m})$, and Region A was constructed as a whole. The planar graph of the excavation is shown in Figure 13.

For a deep excavation, a temporary road used for construction is necessary to transport soils or construction machines between the ground surface and the bottom of the excavation. Figure 13 shows the transportation paths (blue arrows) in the 5th excavation and 8th excavation. The paths were covered by pavement made using cast-in-place concrete with a $30^{\circ}$ horizontal angle, of which two sides formed slopes that maintained the stability of the road. Note that the temporary roads were moved to the north site of the excavation (see Figure 13(b)) when the excavation reached the design depth.
The construction of the underground passage connecting the north site and Region A was a critical part of this case history (see Figure 13(b)). The underground passage was constructed using a top-down construction method to recover the traffic. The top-down construction method can shorten the construction period but increases the risks and costs of construction. As known, using the top-down construction method, the different deformations of the columns may frequently cause cracks or failures of the floor slabs. Moreover, the heavy cars and machines that travel through the passage may possibly influence the stability of columns. Thus, the bearing capacity of the column needs to be considered.

The underground passage not only will serve as a passage connecting two business zones for people after construction is completed but also is the passage used to transport soils and machines during construction. Two passages, Passage 1 and Passage 2, used during construction are shown in Figure 14. Passage 1 and Passage 2 were located on the east side of $-2 \mathrm{~F}$ and in the middle region of $-4 \mathrm{~F}$, respectively. Passage 1 began to be used when the excavation of the soils of $-2 \mathrm{~F}$ was completed. After the floor slab of $-2 \mathrm{~F}$ was installed, the soils around Passage 2 were first excavated. The soils of other regions in $-3 \mathrm{~F}$ and $-4 \mathrm{~F}$ remained, which formed a slope near Passage 2. The passage used for construction was shifted from Passage 1 to Passage 2 after the construction of Passage 2 was completed. The overcharge on the passages and the asymmetric excavation method, which were not considered during the design processes, may possibly cause instabilities of the columns. According to the difference distributions of the loads, the columns influenced by the construction passages were divided into three column types: columns near Passage 1 (Column A), columns in the slope (Column B), and columns near Passage 2 (Column C). A series of numerical investigations were carried out to study the effects of overcharges and the stabilities of columns in previous works [61]. The calculated results for the three types of 
TABLE 11: The calculated results for three types of columns.

\begin{tabular}{lcccc}
\hline Column type & Vertical deformation $(\mathrm{mm})$ & Horizontal deformation $(\mathrm{mm})$ & Shear force $(\mathrm{kN})$ & 63.8 \\
\hline Column A & -9.57 & 2.19 & 353.5 & 13173.6 \\
Column B & -13.27 & 2.13 & 162.1 & 14031.7 \\
Column C & -12.51 & 2.65 & 13599.6 \\
\hline
\end{tabular}

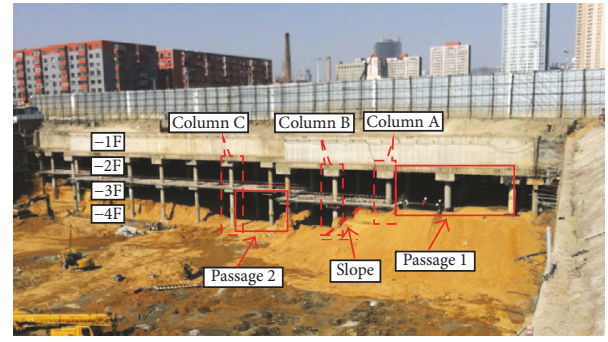

FIGURE 14: Underground passage (under construction).

columns are listed in Table 11. Comparing Column A and Column C, the deformations and internal forces of Column A were both smaller than those of Column $\mathrm{C}$, which shows that Column A near Passage 1 was safer than Column $C$ near Passage 2. The floor slab of $-3 \mathrm{~F}$ was not installed, which increased the effective length of Column $\mathrm{C}$ and weakened its stability, resulting in the increase of the deformations and internal forces. As shown in Table 11, the deformation (vertical deformation) and internal forces of Column B were the largest among the three types of columns, especially for the shear force. Thus, more attention needs to be paid to the service behavior of Column $\mathrm{C}$ during the construction of an underground passage.

\subsection{Monitoring of the Deep Excavation}

5.2.1. Anchor Tests. Anchor tests aim to obtain the pullout capacity and the performances of tieback anchors. In China, the anchors used in projects need to be tested based on the requirement of CECS 22:2005 [62], the technical specification for ground anchors. According to CECS 22:2005, three types of anchor tests need to be carried out: the acceptance test, the basic test, and the creep test. Tieback anchors were tested in another site in Shenyang in gravelly sand, with a free length of $6 \mathrm{~m}$ and a fixed length of $8 \mathrm{~m}$. The load-displacement responses of the acceptance test and the basic test are shown in Figures 15 and 16, respectively.

For the acceptance test, the tieback anchor was testloaded in accordance with the requirements of CECS 22:2005. This involved the application of a load from $0.1 N_{k}\left(N_{k}\right.$, the characteristic value of the axial force of an anchor) up to $1.4 N_{k}$. The load was increased in stages to $10 \%, 40 \%, 60 \%$, $80 \%, 100 \%, 120 \%$, and $140 \%$ of the $N_{k}$ value. Measurements of the anchor displacements were made using LVDTs. As shown in Figure 15, the tieback anchor was loaded up to $602 \mathrm{kN}$ and then unloaded to $43 \mathrm{kN}\left(0.1 N_{k}\right)$. The load-displacement response showed that the anchor had a good service performance under the load of $602 \mathrm{kN}$, without obvious yield

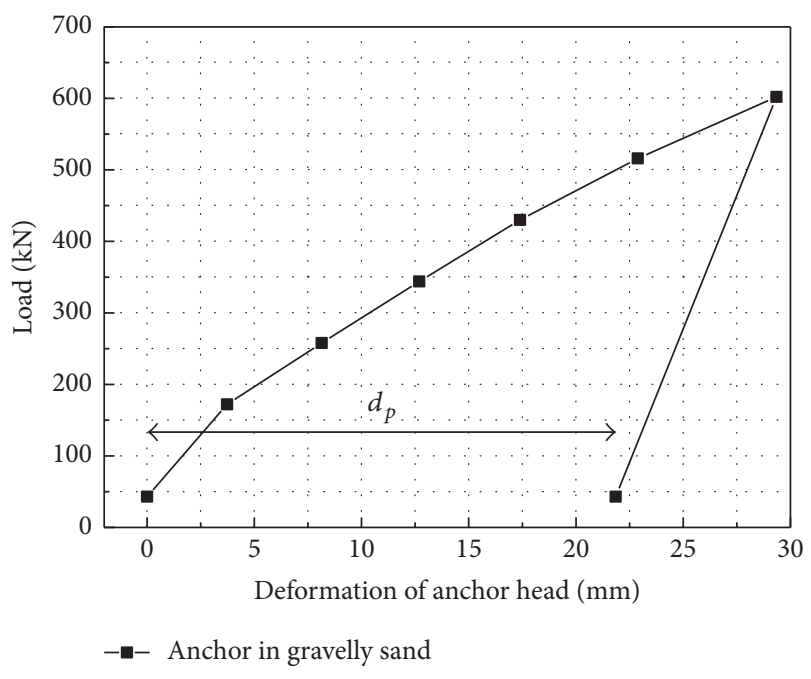

FIGURE 15: Load-displacement response of the acceptance test.

characteristics. After the load cycle, the plastic deformation $d_{p}$ and the total deformation $d_{t}$ were $21.8 \mathrm{~mm}$ and the $29.4 \mathrm{~mm}$, respectively. According to CECS 22:2005, the total deformation $d_{t}$ should satisfy the following expression:

$$
80 \% \times \Delta e_{1}<d_{t}<\Delta e_{2},
$$

where $\Delta e_{1}$ is the tendon elastic deformation of the free length of the anchor and $\Delta e_{2}$ is the tendon elastic deformation of the free length and half of the fixed length of the anchor. The tendon elastic deformation can be calculated using the following equation:

$$
\Delta e=L \cdot \frac{F}{\left(A_{t} \cdot E_{t}\right)},
$$

where $\Delta e$ is the tendon elastic deformation; $L$ is the calculated tendon length; $F$ is the difference between the peak cycle load and datum load ( $559 \mathrm{kN}) ; A_{t}$ is the tendon cross-sectional area $\left(560 \mathrm{~mm}^{2}\right)$; and $E_{t}$ is the tendon elastic modulus $(200 \mathrm{GPa})$. According to the verification, $d_{t}$ was greater than $0.8 \Delta e_{1}(24.0 \mathrm{~mm})$ and less than $\Delta e_{2}(50 \mathrm{~mm})$.

For the basic test, the tieback anchor was tested using 6 loading cycles. The load-deformation curves of the basic test for the selected anchor are presented in Figure 16. The plastic deformation $d_{p}$ was measured after the anchor had been unloaded to a datum load from a given load in the cyclic loading. The elastic deformation $d_{e}$ was the difference between the total deformation $d_{t}$ and the plastic deformation $d_{p}$. The test was conducted with the load up to an estimated ultimate resistance $Q_{u}$, which was defined to be $780 \mathrm{kN}$ (design load $Q_{d}=430 \mathrm{kN}$ ). For the cyclic loading, the peak 


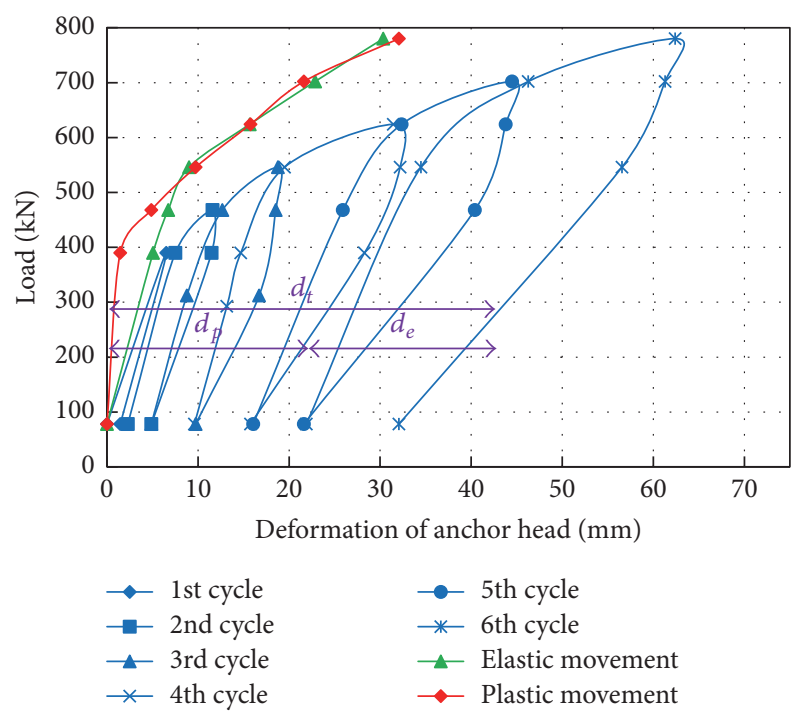

FIGURE 16: Load-displacement response under cyclic loading.

loads of the six cycles were set equal to $50 \%, 60 \%, 70 \%, 80 \%$, $90 \%$, and $100 \%$ of $Q_{u}$. After each cycle, the tested anchor was shown to exhibit more flexible responses upon reloading. This may be attributed to the increasing peak load, which enabled a longer fixed length. As shown in Figure 16, the anchor was verified to safely carry the load, and no yield points occurred on the load-plastic deformation curve.

In addition to the acceptance test and the basic test, the creep test is another important anchor test that aims to verify the long-term performance of an anchor based on the measured creep rate. For anchors in sandy soils in Shenyang, prestress loss caused by anchor creep is not significant. Due to this, the creep test is not often carried out for the construction of a ground anchor.

Anchor tests are also required according to the European codes EN 1537: 2013 and ISO 22477-5: 2009 and the American code FHWA-IF-99-015. For the European code, the basic test is called a suitability test. For the American code, the acceptance test and basic test are called the proof test and performance test, respectively. The processes of the tests for the three codes are similar, except for some detailed differences, such as the peak load, the start and end time of each cycle, the capacity criterion, and the test quality of anchors. The Chinese code CECS 22:2005 is much more similar to the American code, which is simpler than the European code.

5.2.2. Prestress Monitoring of Tieback Anchors. For a tieback anchored pile wall, the quality of the tieback anchors can influence the performance of the whole supporting system. Thus, the steel wales and their weld seams need to be constructed in accordance with the design documents to keep the fixing of anchor heads reliable. The holding-load tension method and overload tension method should be adopted during the process of anchor installation. The tension load should be set to $105 \%$ to $110 \%$ of $Q_{d}$ (the design load). If the prestress loss is larger than $10 \%$ of $Q_{d}$ during a period of 48 hours after an anchor is locked, the anchors should be tensioned to compensate [63] (Metallurgical Department Building Research Institute, 2001).

At the beginning of 2013, part of the weld seams connecting steel wales cracked due to the inferior construction quality (see Figure 17). Figure 18 illustrates the prestress of four tieback anchors of M12 for a period of 160 days. Figure 18 shows that anchor $L 4$ experienced a large prestress loss, which introduced risk to the excavation. Thus, in early March, the steel wales in the 4 th row were rewelded, and the anchors in the 4 th row were tensioned to compensate.

The anchors initially showed different degrees of prestress loss after they were installed (Figure 18). This stage was called the fast loss stage of prestress. Because the frequency of monitoring was not sufficient at this initial time, some prestress loss data of anchors were missed. The complete monitoring data were analyzed and are shown in Figure 19. According to the previous works of Yu et al. (2005) [64], the prestress losses were mainly caused by anchorage device slipping and ground deformation that occurred when the anchors were initially locked. The function relationship between anchor prestress and time is as follows:

$$
\begin{aligned}
& F(t)=F_{0} \exp \left(-\frac{t}{a t+b}\right), \\
& \omega(t)=\frac{F(t)}{F_{0}}=\exp \left(-\frac{t}{a t+b}\right),
\end{aligned}
$$

where $t$ is the amount of time that has passed after the anchor is locked; $F(t)$ is the prestress of the anchor at the time $t ; F_{0}$ is the initial prestress after the anchor is locked; $\omega(t)$ is the prestress function; and $a$ and $b$ are tested constants, which are related to the geotechnical characteristics.

The in situ measured data were compared with the fitting curves using the Origin program, and $a$ and $b$ were calculated to be 2.2648 and 2.31, respectively (see Figure 19). As shown in Figure 19, the prestress loss was great during the first three days after the anchors were locked, accounting for approximately $82 \%$ of the total prestress loss (the fast loss stage). From the fourth day to the tenth day after the anchors were locked, the prestress loss was also significant but tended to be gentle, accounting for approximately $15 \%$ of the total prestress loss (the slow loss stage). After these two stages, the prestress loss underwent a slight increase (the stable stage).

5.2.3. Horizontal Deformation of Pile Head. The horizontal deformations of the five pile heads on the east side of the deep excavation are shown in Figure 20. The maximum deformation of a pile head occurred on the east side because the length of the east side between two corners was relatively long. On the east side, the maximum horizontal deformation of a pile head was approximately $30.69 \mathrm{~mm}$, which is equal to $0.13 \% H_{e}$, while that on the west side and south side was $19.91 \mathrm{~mm}$ and $9.64 \mathrm{~mm}$, respectively.

The processes of soil excavation and tieback installation were mainly carried out from early December 2012 to late January 2013. After that time, the temperature dropped, causing the construction to stop. The horizontal deformations of the pile heads increased rapidly during the soil excavation (see Figure 20), in contrast to that which occurs in soft 


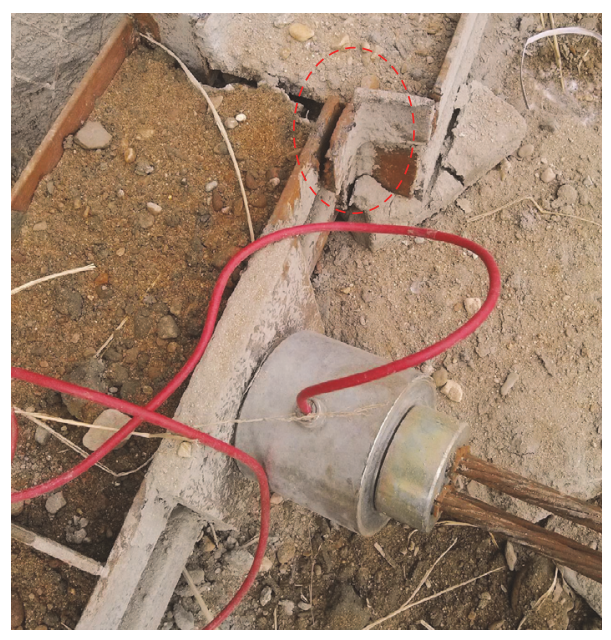

(a)

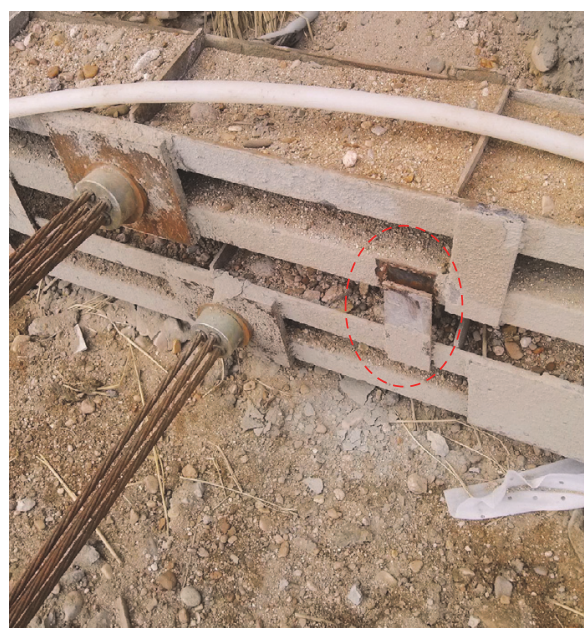

(b)

FIGURE 17: Weld cracking in steel wales.

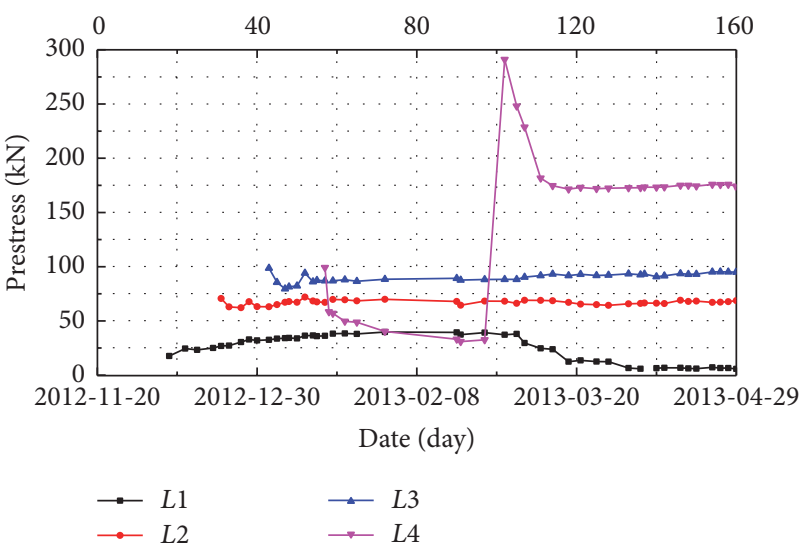

Figure 18: Prestress of the anchor cable of M12.

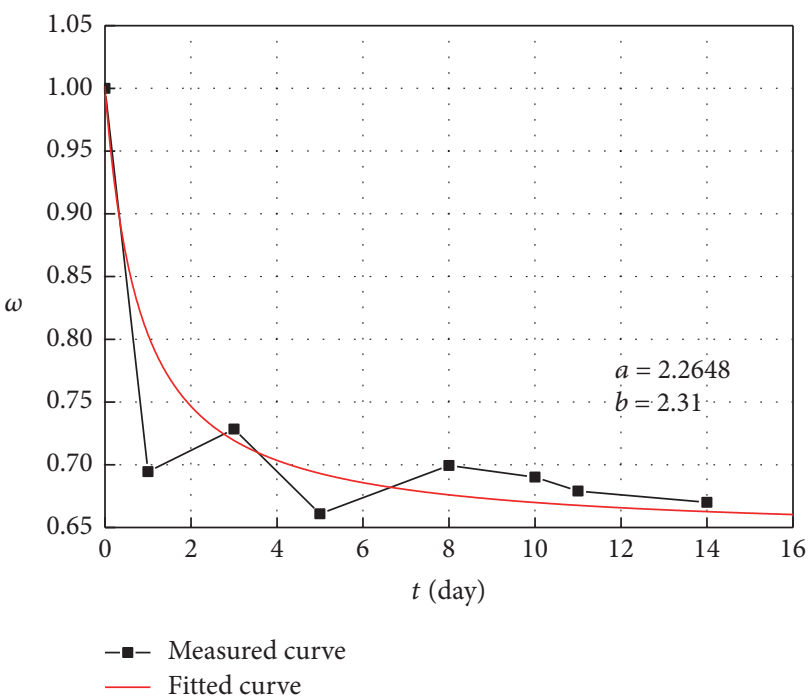

FIGURE 19: Change in the prestress rate of the anchor cable with time.

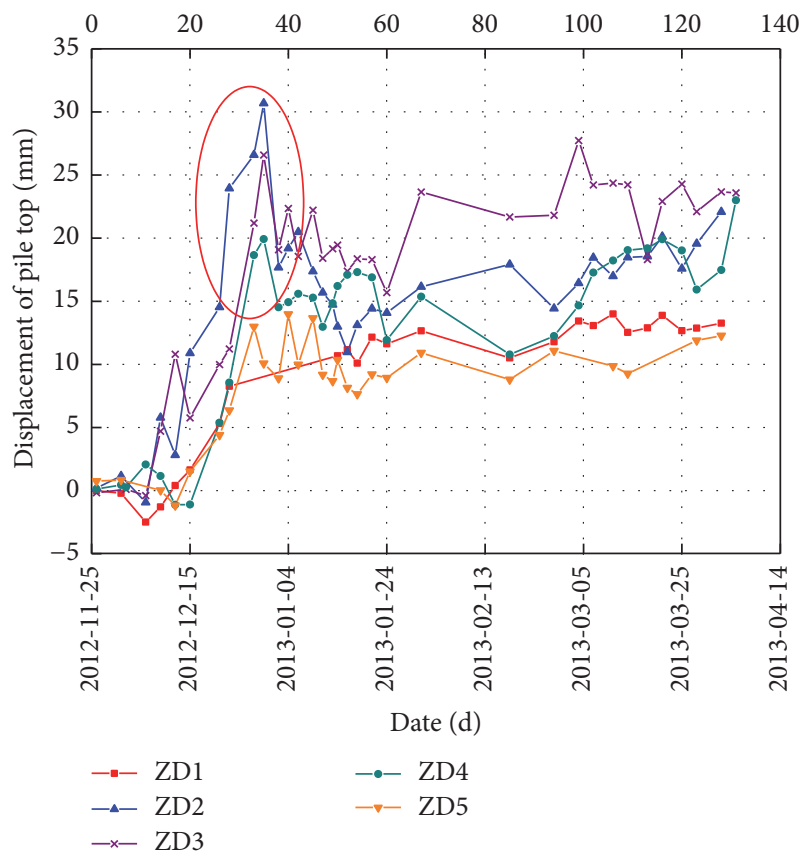

FIGURE 20: Horizontal deformations of pile heads.

clay. The rheological property of soft clay makes retaining structures and soils move with time.

In late December 2012, a large number of rebar and concrete formworks were placed on the ground surface behind the pile wall, with a distance of $3 \mathrm{~m}$ to $10 \mathrm{~m}$ from the edge of the excavation and just behind the monitoring point, ZD2. The overweight loads caused significant deformation, and the deformation rate of ZD2 increased to $4.3 \mathrm{~mm} / \mathrm{d}$, which exceeded the critical value set by GB50497-2009 [65]. After removing the overweight loads, the horizontal deformation decreased to a normal value. 
5.2.4. Artificial Dewatering. Artificial dewatering methods, such as the tube well method, vacuum well method, and ejector well method, are recommended in China. The application scope of each method is different. The vacuum well method and ejector well method are suitable for clay, silt, and sand, of which the permeability coefficients are less than $20 \mathrm{~m} / \mathrm{d}$, and the dewatering depth is less than $20 \mathrm{~m}$. The tube well method is suitable for soils of which the permeability coefficients are less than $200 \mathrm{~m} / \mathrm{d}$. The permeability coefficients of in situ soils in this excavation case range from $40 \mathrm{~m} / \mathrm{d}$ to $80 \mathrm{~m} / \mathrm{d}$, measured via pumping tests. As a result, the tube well method was selected for this project.

In this deep excavation case, the dewatering wells were set around three sides of the excavation, except the north side (see Figure 1), at a distance of $3 \mathrm{~m}$ behind the piles and with a $25 \mathrm{~m}$ spacing distance between each well. The length of the dewatering well was $38 \mathrm{~m}$, with a diameter of $0.4 \mathrm{~m}$. The length of the filter tube in each well was $32 \mathrm{~m}$. Submersible pumps were selected to be installed in the wells as the dewatering devices. Each well could pump $60 \mathrm{~m}^{3}$ to $80 \mathrm{~m}^{3}$ of water per hour.

The total length of the drainage line was $765 \mathrm{~m}$, including twenty-nine dewatering wells and three water collecting basins with a size of $1 \mathrm{~m} \times 1.5 \mathrm{~m} \times 2 \mathrm{~m}$. The drainage line used steel tube drainage pipes with a diameter of $0.426 \mathrm{~m}$. The water pumped out of the ground was drained to the city's drainage system through the drainage line.

After construction dewatering, the groundwater level declined, resulting in the pore water pressure in the ground reducing and the effective stress of the soil skeleton increasing. As a result, the soil consolidation caused the ground surface to settle. Because the permeability coefficient of the sandy soils in Shenyang is large, the influence scope of dewatering is wide. The surrounding buildings and underground pipeline were affected by dewatering to some extent. According to the code JGJ 120-2012, the influence radius of construction dewatering in an unconfined aquifer is

$$
R=2 s_{w} \sqrt{k H},
$$

where $R$ is the influence radius; $s_{w}$ is the drawdown of dewatering wells; $k$ is the permeability coefficient; and $H$ is the thickness of the unconfined aquifer.

In this excavation case, $s_{w}$ was approximately $23 \mathrm{~m}$, which caused the influence radius $R$ to be $2100 \mathrm{~m}$. According to the measurements of many excavation cases in Shenyang, no construction accidents, such as ground cracking and building cracking, caused by dewatering occurred, and the deformation of the ground and buildings was mainly caused by the actual excavating process. According to Li's investigation [66], from the 1950s to the 1980s, groundwater was supplied to citizens in Shenyang. Because of the large water consumption, the groundwater level in most regions of Shenyang was approximately $30 \mathrm{~m}$ below the ground surface at that time. At the end of the 1980s, the groundwater exploitation reduced, causing the groundwater level to rise gradually (to approximately $8 \mathrm{~m}$ below the ground surface). Hence, shallow soils in Shenyang were overconsolidated. If the drawdown of the groundwater level does not extend

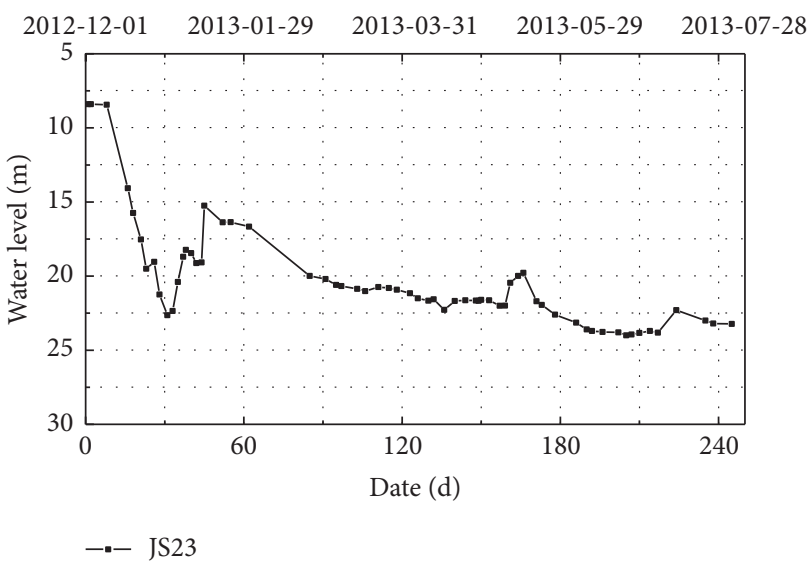

FIGURE 21: Groundwater level measured at JS23.

deeper than the maximum value recorded in history, only restorable elastic compression occurs in soils, which is much smaller than the deformation of normally consolidated soils. The aquifer in Shenyang mainly contains medium-coarse sand and gravelly sand; the consolidation behavior was shown to mainly involve primary consolidation. The secondary consolidation in coarse-grained sand caused by the viscous effect is not significant.

The groundwater level was measured throughout the excavation. Figure 21 shows the groundwater level for a period of 250 days. During the first 50 days, the groundwater level values were measured at the JS23 well, which was located at the southeast side of the excavation. After 50 days, the measurement point was moved to an inclinometer inside the ground near JS23. The stable groundwater level before dewatering was approximately $8 \mathrm{~m}$. Dewatering was not needed until the excavation depth reached $6 \mathrm{~m}$. As shown in Figure 21, the water level in the well decreased rapidly and unstably, while that in the inclinometer, which realistically depicts the groundwater level, changed smoothly.

\section{Conclusions}

The design, construction, testing, and monitoring of a tieback anchored pile wall were described. By back-analyzing Young's modulus, FEM models using the MC model and the HS model were established to compare with the design results calculated using a design program. The similarities and differences between the Chinese and European design standards were described, and the design results were analyzed through a design case. The crucial construction method and the monitoring results of the case history were presented. The performance of the tieback anchored pile wall was studied based on the test results and measurements. The following conclusions were drawn:

(1) Based on the back analysis of the deformation parameters of in situ soils, the horizontal wall deformations and ground settlements calculated using the HS model and the MC model agreed well with the observations. However, the MC model resulted in slightly conservative ground settlements. Thus, for the 
FEM analysis of a deep excavation, the MC model is not appropriate. The design estimates of deformation and resistance obtained using the elastic method were larger than the FEM results and the observations. The overestimation of the results can make the design more secure but less economical in practice.

(2) For the excavation supported by a tieback anchored pile wall, the ground behind the wall was reinforced by prestressed tieback anchors, resulting in the sliding scope extending further behind the wall. The potential slip surface predicted by the limit equilibrium method showed a significant deviation with respect to the results of the strength reduction method. The strength reduction method is recommended to predict the potential slip surface of a tieback anchored pile wall supporting excavation.

(3) Compared with the Chinese design standards, the employment of the reliability theory based on the limit states and the division of partial factors in the European design standards are clearer. In the European design standard, three design approaches, DA1, DA2, and DA3, are recommended for conducting verifications, which distinguish the distribution of partial factors in terms of actions, material properties, and resistances. However, the Chinese design standard tends to use the comprehensive partial factor $\gamma_{F}$ and the importance factor $\gamma_{0}$ to create the reliability design. Tieback anchored pile wall designed using the European design standards will take more risk than that designed using the Chinese design standards.

(4) According to the design case of a tieback anchored pile wall, the Deep Excavation software (the elastic method) is more conservative than the classical method for the Chinese code. For the European code, DA2 is the most conservative design approach because of its use of partial factors of resistance. DA3 is the most insecure of the three approaches. Comparing the Chinese and European codes, the deviation between the design results is small. The Chinese code focuses on the design result, while the European code focuses on the design process.

(5) The test results showed that the tieback anchors in gravelly sand had a good performance under a load of $780 \mathrm{kN}$. When the anchors were initially locked, the anchor prestress had an exponential relationship with time. The prestress loss increased in three stages: the fast loss stage, the slow loss stage, and the stable stage. The holding-load tension method and overload tension method are effective in reducing the prestress loss. Engineers need to pay attention to the fast loss stage of tieback anchors and retension the tieback anchors when the prestress loss is excessive.

(6) According to the observed deformations of the pile heads, the deformations of the structures and ground in sandy soils showed only a slight variation with time. The consolidation behavior of sandy soil was shown to mainly involve primary consolidation. Therefore, the frequency of deformation observation is suggested to be increased after the soil excavated and the retaining structure needs to be installed in time.

\section{Conflicts of Interest}

No potential conflicts of interest were reported by the authors.

\section{Acknowledgments}

This work was supported by the National Natural Science Foundation of China (Grant no. 51578116).

\section{References}

[1] A. Adekunte, D. Madsen, N. Margetson, and L. Quinn, "Predicted and observed performance of an anchored retaining wall in granite," in Ground Anchorages and Anchored Structures in Service 2007: Proceedings of the Two Day International Conference Organised by the Institution of Civil Engineers, pp. 427-437, Thomas Telford Publishing, London, UK, November 2007.

[2] C. Veder, Excavation of Trenches in the Presence of Bentonite Suspension for the Construction of Impermeable and LoadBearing Diaphragms. Grouts and Drilling Muds in Engineering Practice, Butterworths, London, UK, 1963.

[3] J.-L. Briaud and Y. Lim, "Tieback walls in sand: Numerical simulation and design implications," Journal of Geotechnical and Geoenvironmental Engineering, vol. 125, no. 2, pp. 101-110, 1999.

[4] P. C. Lambe and L. A. Hansen, Design and Performance of Earth Retaining Structures. American Society of Civil Engineers Geotechnical Publication No. 25, 1990.

[5] D. E. Weatherby, "Behavior of tiedback, h-beam walls and recommendations for their design," in Proceedings of the 2010 Earth Retention Conference - Earth Retention Conference 3, pp. 170-187, USA, August 2010.

[6] S. Khoshnevisan, L. Wang, and C. H. Juang, "Response surfacebased robust geotechnical design of supported excavationspreadsheet-based solution," Georisk: Assessment and Management of Risk for Engineered Systems and Geohazards, vol. 11, no. 1, pp. 90-102, 2017.

[7] R. B. Peck, "Deep excavation \&amp; tunneling in soft ground. Stateof-the-art-report," in Proceedings of the 7th International Conference of Soil Mechanics and Foundation Engineering, International Society for Soil Mechanics and Geotechnical Engineering, pp. 225-281, Mexico, 1969.

[8] T. D. O'Rourke, "Ground movements caused by braced excavations," Journal of Geotechnical and Geoenvironmental Engineering, vol. 107, no. 9, pp. 1159-1178, 1981.

[9] R. J. Finno, D. K. Atmatzidis, and S. B. Perkins, "Observed performance of a deep excavation in clay," Journal of Geotechnical Engineering, vol. 115, no. 8, pp. 1045-1064, 1989.

[10] C.-Y. Ou, J.-T. Liao, and H.-D. Lin, "Performance of diaphragm wall constructed using top-down method," Journal of Geotechnical and Geoenvironmental Engineering, vol. 124, no. 9, pp. 798808, 1998.

[11] R. J. Finno, J. T. Blackburn, and J. F. Roboski, "Threedimensional effects for supported excavations in clay," Journal of Geotechnical and Geoenvironmental Engineering, vol. 133, no. 1, pp. 30-36, 2007. 
[12] Y. Tan and B. Wei, "Observed behaviors of a long and deep excavation constructed by cut-and-cover technique in Shanghai soft clay," Journal of Geotechnical and Geoenvironmental Engineering, vol. 138, no. 1, pp. 69-88, 2011.

[13] D. H. Seo, B. S. Chang, S. S. Jeong, and S. I. Kim, "Evaluation of the sequential behavior of tieback wall in sand by small scale model tests," Journal of the Korean Geotechnical Society, vol. 15, no. 3, pp. 113-129, 1999.

[14] R. J. Finno and J. F. Roboski, “Three-dimensional responses of a tied-back excavation through clay," Journal of Geotechnical and Geoenvironmental Engineering, vol. 131, no. 3, pp. 273-282, 2005.

[15] J. Roboski and R. J. Finno, "Distributions of ground movements parallel to deep excavations in clay," Canadian Geotechnical Journal, vol. 43, no. 1, pp. 43-58, 2006.

[16] J. F. Roboski, Three-Dimensional Performance And Analyses of Deep Excavations [M.S. thesis], Northwestern University, 2004.

[17] K. Terzaghi, Theoretical Soil Mechanics, John Wiley \& Sons, New York, NY, USA, 1943.

[18] D. W. Taylor, Fundamentals of Soil Mechanics, John Wiley \& Sons, New York, NY, USA, 1948.

[19] J. Brinch Hansen, "Earth Pressure Calculations," Tech. Rep., The Danish Technical Press, Copenhagen, Denmark, 1953.

[20] J. Brinch Hansen, "Limit design and safety factors in soil mechanics," Limit Design and Safety Factors in Soil Mechanics. Danish Geotechnical Institute, Copenhagen, Bulletin No. 1, 1956.

[21] B. Simpson, "Partial factors: where to apply them," in Proceedings of the LSD 2000: International Workshop on Limit State Design in Geotechnical Engineering, pp. 125-136, 2000.

[22] T. L. L. Orr, "Selection of characteristic values and partial factors in geotechnical designs to Eurocode 7," Computers \& Geosciences, vol. 26, no. 3-4, pp. 263-279, 2000.

[23] D. E. Becker, "Eighteenth Canadian geotechnical colloquium: Limit states design for foundations. Part I. An overview of the foundation design process," Canadian Geotechnical Journal, vol. 33, no. 6, pp. 956-983, 1996.

[24] Y.-S. Li, X. Duan, Y. Li, and X.-P. Li, “Comparative research on design approaches on retaining structure for deep foundation pits in Chinese and European geotechnical design codes," Chinese Journal of Geotechnical Engineering, vol. 36, pp. 77-81, 2014 (Chinese).

[25] N.-K. Kim, "Performance of tension and compression anchors in weathered soil," Journal of Geotechnical and Geoenvironmental Engineering, vol. 129, no. 12, pp. 1138-1150, 2003.

[26] D. C. Konstantakos, "Online database of deep excavation performance and prediction," in 6th International Conference on Case Histories in Geotechnical Engineering, 2008.

[27] T. Tamano, H. Q. Nguyen, M. Kanaoka, Y. Fuseya, and W. Tonosaki, "Field Tests and Numerical Investigation of Splits Anchors in Structured Clay," 2006.

[28] N. Uğur Terzi, G. I. Daldal, and S. Yildirim, "Monitoring a grouted anchor in a reinforced structure," Experimental Techniques, vol. 35, no. 2, pp. 47-54, 2011.

[29] S.-T. Hsu, "Behavior of pressure-grouted anchors in gravel," Canadian Geotechnical Journal, vol. 49, no. 6, pp. 719-728, 2012.

[30] S. G. Li, J. Y. Han, J. J. Shi, and W. Zhao, "Field test on steel pipe jacking by STS method," Journal of Northeastern University (Natural Science), vol. 37, no. 10, pp. 1469-1473, 2016 (Chinese).

[31] NBS, Technical specification for retaining and protection of building foundation excavations. JGJ 120-2012. National Bureau of Standards of China (NBS), Beijing, China; 2012, (in Chinese).
[32] W.-M. Xu and Y.-M. Tu, "Landslide analysis and reinforcement design of the pit-in-pit," Rock and Soil Mechanics, vol. 31, no. 5, pp. 1555-1563, 2010 (Chinese).

[33] J. H. Liu and X. Y. Hou, Excavation Engineering Manual, 1997.

[34] X. N. Gong, Deep Excavation Engineering Design And Construction Manual, 1998.

[35] M. Khoiri and C.-Y. Ou, "Evaluation of deformation parameter for deep excavation in sand through case histories," Computers \& Geosciences, vol. 47, pp. 57-67, 2013.

[36] T. Schanz, P. A. Vermeer, and P. G. Bonnier, "The hardening soil model: Formulation and verification," Beyond 2000 in computational geotechnics, pp. 281-296, 1999.

[37] R. B. J. Brinkgreve, E. Engin, W. M. Swolfs et al., PLAXIS 3D, 2010, Plaxis Company, Delft, Netherlands, 2010.

[38] M. Khoiri, C.-Y. Ou, and F.-C. Teng, "A comprehensive evaluation of strength and modulus parameters of a gravelly cobble deposit for deep excavation analysis," Engineering Geology, vol. 174, no. 8, pp. 61-72, 2014.

[39] J. M. Duncan and C. Y. Chang, "Nonlinear analysis of stress and strain in soils," Journal of the Soil Mechanics and Foundations Division, 1970.

[40] J. E. Bowles, Foundation Analysis and Design, McGraw-Hill Company, New York, NY, USA, 4th edition, 1988.

[41] D. G. Fredlund and J. Krahn, "Comparison of slope stability methods of analysis," Canadian Geotechnical Journal, vol. 14, no. 3, pp. 429-439, 1977.

[42] G. W. Clough and L. A. Hansen, "Clay anisotropy and braced wall behavior," Journal of the Geotechnical Engineering Division, vol. 107, no. 7, pp. 893-913, 1981.

[43] B. Ukritchon, A. J. Whittle, and S. W. Sloan, "Undrained stability of braced excavations in clay," Journal of Geotechnical and Geoenvironmental Engineering, vol. 129, no. 8, pp. 738-755, 2003.

[44] K. Terzaghi, R. B. Peck, and G. Mesri, Soil Mechanics in Engineering Practice, John Wiley \& Sons, 1996.

[45] Z. Gang, Deep Foundation Pit Engineering Design Theory and Engineering Application, 2010.

[46] H. Faheem, F. Cai, K. Ugai, and T. Hagiwara, “Two-dimensional base stability of excavations in soft soils using FEM," Computers \& Geosciences, vol. 30, no. 2, pp. 141-163, 2003.

[47] M.-F. Chang, "Basal stability analysis of braced cuts in clay," Journal of Geotechnical and Geoenvironmental Engineering, vol. 126 , no. 3, pp. 276-279, 2000.

[48] L. Bjerrum and O. Eide, "Stability of strutted excavations in clay," Géotechnique, vol. 6, no. 1, pp. 32-47, 1956.

[49] M.-S. Huang, X.-Y. Song, and H.-L. Qin, "Basal stability of braced excavations in $\mathrm{K} \sim 0$-consolidated soft clay by upper bound method," Chinese Journal of Geotechnical Engineering, vol. 30, no. 2, pp. 250-255, 2008 (Chinese).

[50] B. EN, Eurocode 7: Geotechnical design-Part 1: General rules, British Standards, UK, 2004.

[51] R. Frank, Designers' Guide to EN 1997-1 Eurocode 7: Geotechnical Design-General Rules, Thomas Telford Ltd, 2004.

[52] C. A. Coulomb, "Essai sur une application des règles des maximis et minimis à quelques problèmes de statique relatifs à l'architecture," in Mèmires de l'Academie des Sciences, vol. 7, pp. 343-382, Mèmires de l'Academie des Sciences, Paris, 1773.

[53] DI, Code of practice for foundation engineering, Dansk Ingeniorforening, Copenhagen, Denmark, 1965. 
[54] CGS, Canadian foundation engineering manual, Canadian Geotechnical Society, Toronto, Canada, 1992.

[55] NRC, National building code of Canada, National Research Council of Canada, Ottawa, Canada, 1995.

[56] ANSI, "Development of a probability based load criterion for American National Standard A58," Tech. Rep. NBS SP 577, American National Standards Institute, National Bureau of Standards, Washington, DC, USA, 1980.

[57] European Committee for Standardization (CEN), Geotechnical design, general rules, Danish Geotechnical Institute, Prestandard (ENV), Copenhagen, Denmark, 1993.

[58] A. J. Bond, B. Schuppener, G. Scarpelli et al., "Eurocode 7: geotechnical design worked examples," in Workshop Eurocode, vol. 7, 2013.

[59] A. Sieminska-lewandowska and M. Mitew-Czajewska, "Design of deep excavations according to Eurocode 7," 18ème Congrès Français de Mécanique, 2007.

[60] C. Y. Ou, Deep Excavation: Theory and Practice, CRC Press, 2006.

[61] H. F. Yu, Research on construction stability of cut and cover reverse method underpass road and analysison deformation characteristics of column [M.S. thesis], Northeastern University, Boston, Mass, USA, 2014.

[62] CECS22:2005 Technical specification for ground anchors. 2005. (in Chinese).

[63] Central Research Institute of Building and Construction Co., Ltd. Specifications for Bolt-Shotcrete Support, China Planning Press, Beijing, China, 2001.

[64] K. B. Yu, K. B. Chen, and M. L. Yang, "Study on prestress loss of prestressed anchor cable," Rock and Soil Mechanics, vol. 26, no. S1, 2005 (Chinese).

[65] MOHURD, Technical Code for Monitoring of Building Foundation Pit Engineering, Beijing, China, 2012.

[66] F. S. Li, Analysis of the Surface Settlement Due to the Dewatering of Subway Engineering in Shenyang [M.S. thesis], Shenyang Jianzhu University, 2009. 


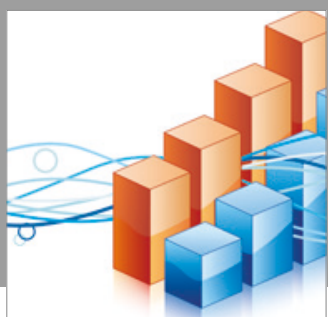

Advances in

Operations Research

vatersals

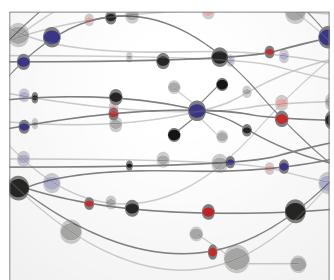

\section{The Scientific} World Journal
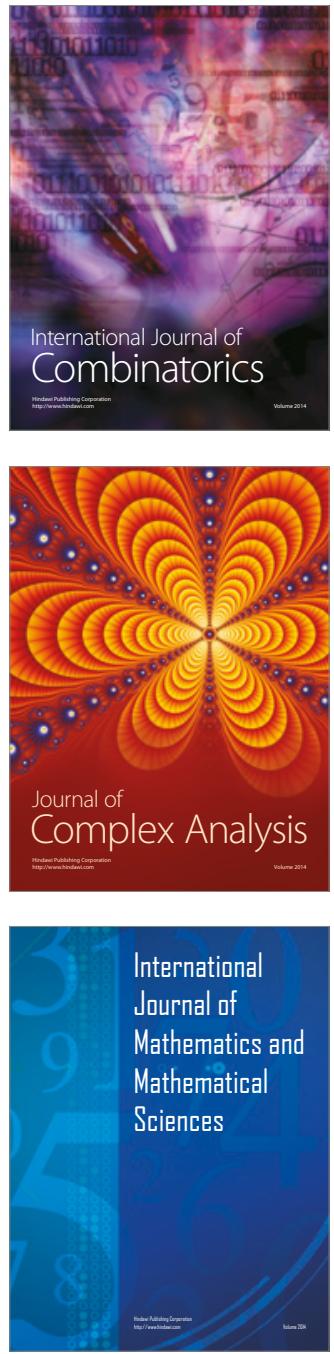
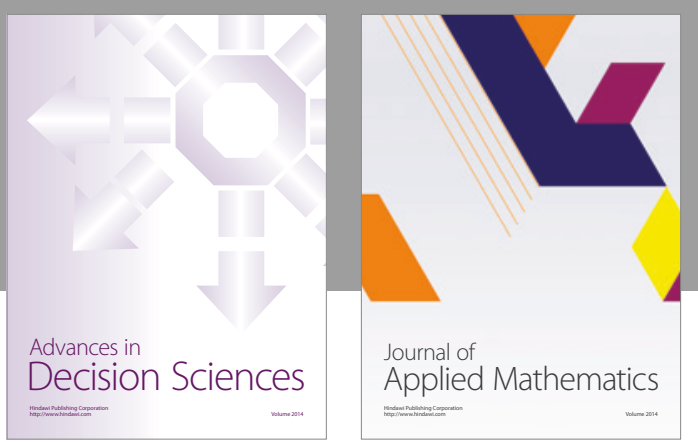

Algebra

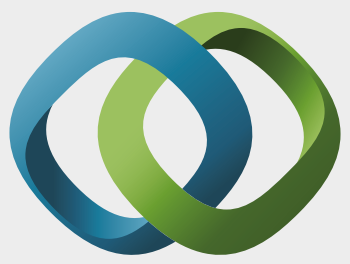

\section{Hindawi}

Submit your manuscripts at

https://www.hindawi.com
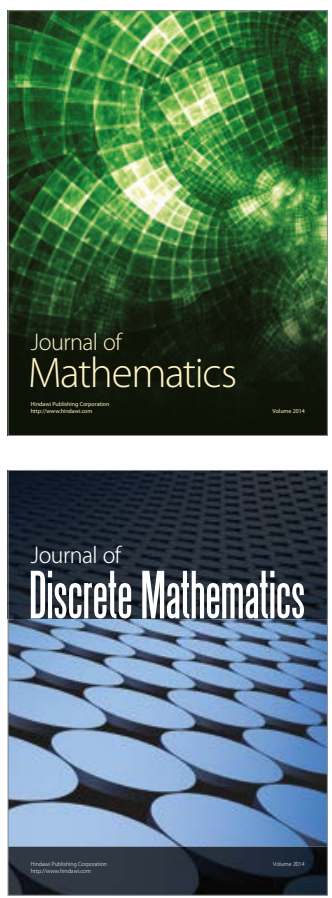

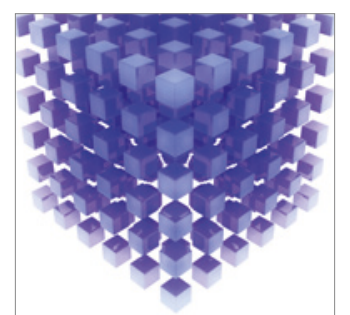

Mathematical Problems in Engineering
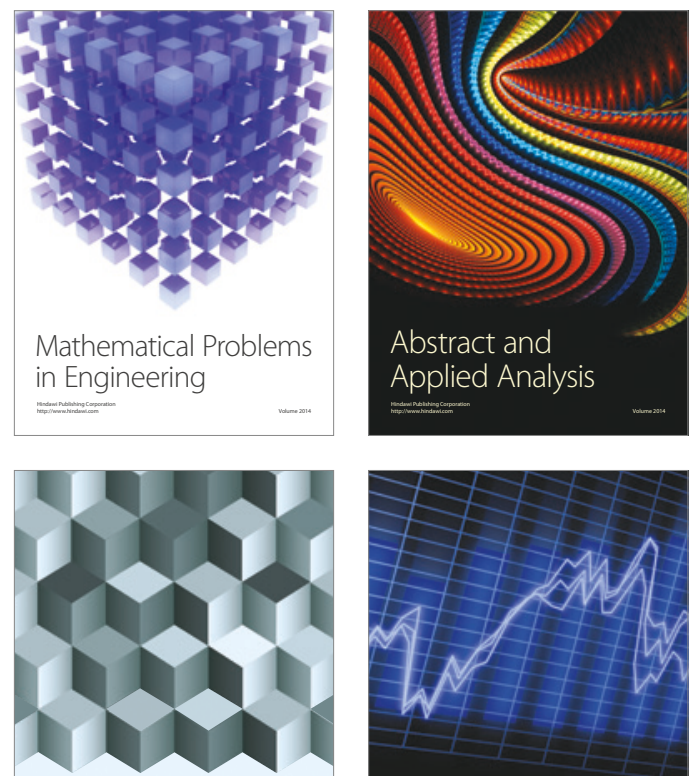

Journal of

Function Spaces

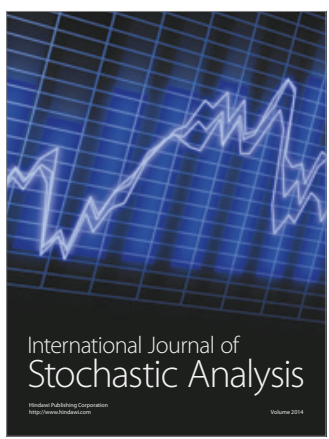

Probability and Statistics
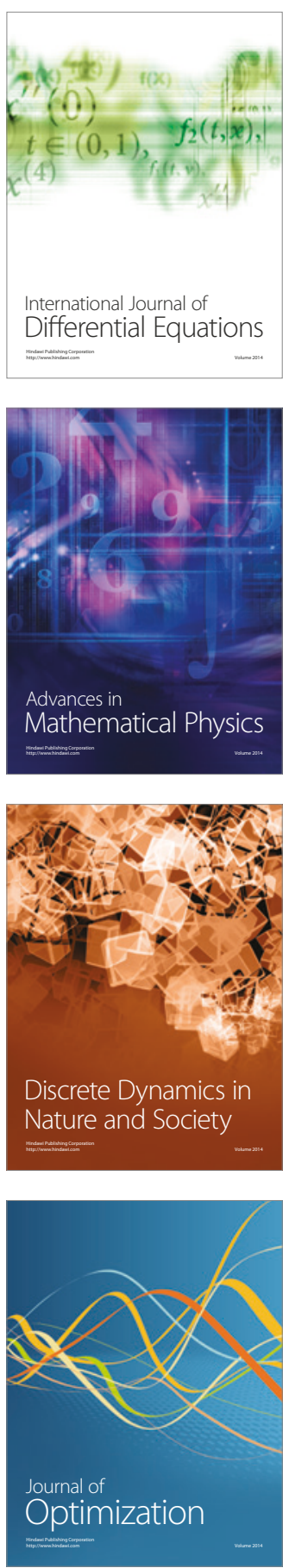